\title{
PREPRINT
}

\section{Quorum sensing in marine biofilms and environments}

\section{Raphaël Lami*}

Sorbonne Université, CNRS, Laboratoire de Biodiversité et Biotechnologies Microbiennes, LBBM, F66650 Banyuls-sur-Mer, France

Full published reference:

Quorum sensing in marine biofilms and environments

Raphaël Lami

Chapter 3 - Quorum Sensing in Marine Biofilms and Environments,

Editor(s): Giuseppina Tommonaro,

Quorum Sensing, Academic Press, 2019,

Pages 55-96,

ISBN 9780128149058 ,

https://doi.org/10.1016/B978-0-12-814905-8.00003-4.

(http://www.sciencedirect.com/science/article/pii/B9780128149058000034)

*Corresponding author: raphael.lami@obs-banyuls.fr

\section{Keywords}

Marine environment, seawater, quorum sensing, quorum quenching, biofilm, holobiont, parasites, surface colonizers, symbionts 


\begin{abstract}
Marine prokaryotes represent abundant and diverse communities across oceans. These organisms are free living, symbionts, parasites or or produce biofilm on very diverse types of marine surfaces. These surfaces include micro- and macro-algae leaves (phycosphere), marine particles, seashore rocks, buoys, microplastics and many others. Such niches favor bacterial concentration and thus different types of bacterial interactions, including quorum sensing. This consists of a mechanism that allows cells to coordinate their gene expression and physiology when a defined number of cells is reached. This review aims to synthesize quorum sensing mechanisms evidenced to date in the marine biofilms and environments. It will first focus on the wide range of chemical compounds involved in these processes and will describe the diversity of bacterial functions regulated by quorum sensing. Then, the implications of quorum sensing at a larger and integrated scale will be examined, including potential biogeochemical implication of quorum sensing expression. Also the importance in quorum sensing in the functioning of diverse holobionts will be addressed, as well as potential industrial applications. Overall, this review will emphasize quorum sensing roles at each stage of biofilm development, whatever the type of marine surfaces on which prokaryotes grow or the host they colonize: crucial in the settlement, maturation and dispersion of marine biofilms.
\end{abstract}




\section{TABLE OF CONTENTS}

1 1. The discovery of and growing interest in quorum sensing in marine environments .4

2 a. 1970s: Quorum sensing was discovered in the marine environment. The Vibrio-squid model. 4

3 b. 1990-2010s: A growing interest in the study of quorum sensing in marine environments

42 2. Overview of prokaryotic diversity and compounds involved in quorum sensing in marine

5 environments and biofilms.

6 a. Experimental approaches to characterize autoinducers in the marine environment .............................................. 6

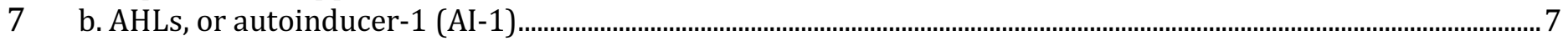

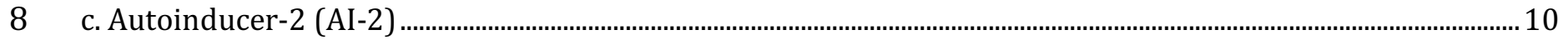

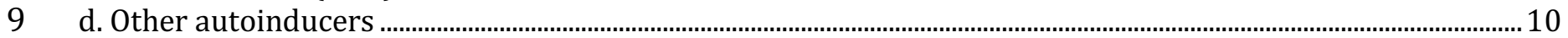

10 e. Diffusion of autoinducers in the marine environment. ........................................................................................ 11

11 f. Vibrio harveyi , a model for the study of quorum sensing in marine bacteria ........................................................12

12 3. Surface biofilms and holobionts: the diversity of microbial habitats enabling quorum sensing in the marine environment.

a. Phycosphere of (micro)-algae and phyllosphere of marine plants ……….......................................................................14

b. Biofilm around sinking marine snow particles ..................................................................................................................... 14

c. Marine microbial mats and other types of subtidal biofilms ...................................................................................15

d. Corals and other cnidarian-associated communities ...................................................................................................

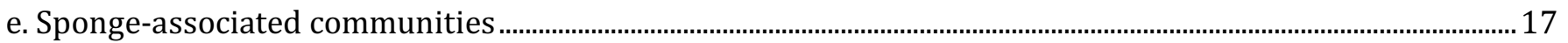

19 4. Diversity of prokaryotic functions regulated by quorum sensing in marine environments.....

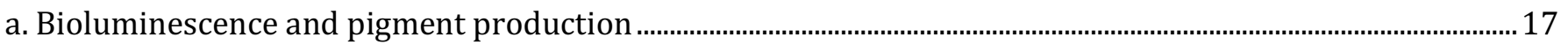

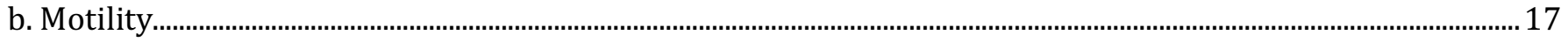

c. Initiation of biofilm formation, maturation and dispersion ....................................................................................... 18

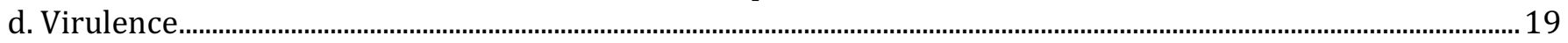

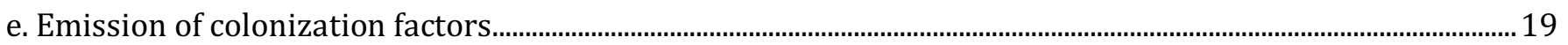

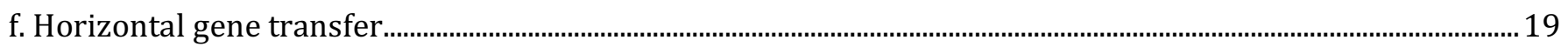

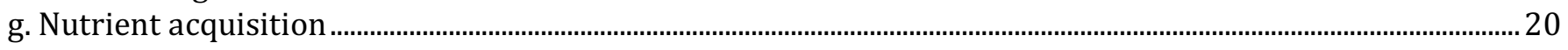

h. Production of antimicrobial compounds .................................................................................................................220

i. Induction and maintenance of phenotypic heterogeneity within a cell population...................................................21

29 5. Sourcing and applying quorum sensing inhibitors in the marine environment: aquaculture

30 protection and innovation in green antifouling.

31 a. A model story: the discovery of antifouling compounds in the red marine alga Delisea pulchra......................22

32 b. Diversity of quorum quenching compounds isolated from marine organisms........................................................23

33 c. Diversity of marine quorum quenching enzymes......................................................................................................24

34 d. Applications for biofouling on marine underwater surfaces …….........................................................................25

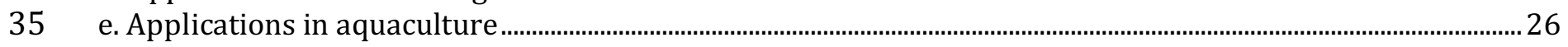

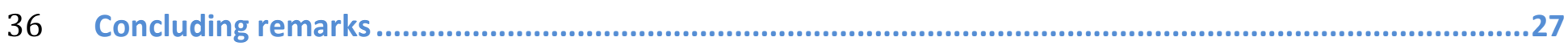


Quorum sensing is suspected to lead to spectacular phenomenon in marine waters. For example, an impressive "Milky sea" of $15400 \mathrm{~km}^{2}$ in the Arabian Sea has been attributed to bioluminescent Vibrio harveyi. These cells were suspected to express quorum sensing to glow and bloom in response to a phytoplankton bloom (Miller et al., 2005). However, since its discovery in the 70s, quorum sensing has been evidenced not only in this type of spectacular bioluminescence but also in many different types of bacterial activities and in phylogenetically very diverse marine cells. This review aims to synthesize the current knowledge about quorum sensing mechanisms in marine biofilms and environments. Maintaining a specific focus on marine waters, we will review the wide diversity of chemical compounds involved in marine quorum sensing, the wide range of biological functions of quorum sensing, and the large number of ecological niches where these processes occur. The last section of this chapter will review applications, targeting the marine environment as a source of quorum sensing-inhibiting compounds and enzymes or focusing on the manipulations of marine bacterial physiologies using quorum quenching-based strategies.

\section{The discovery of and growing interest in quorum sensing in marine environments}

a. 1970s: Quorum sensing was discovered in the marine environment. The Vibrio-squid model.

The concept of quorum sensing referring to a population density-based physiological response of bacterial cells was introduced in the 90s (Fuqua et al., 1994). However, most of the observations that led to the elaboration of this concept were acquired from experiments conducted by marine scientists during the 70s. During this decade, a lot of data were collected on Vibrio fischeri strains that were able to colonize the light organ of the Hawaiian bobtail squid Euprymna scolopes, where they produce bioluminescence (Nealson et al., 1970, Greenberg et al., 1979). In particular, a density-dependent phenotype was originally noted in this symbiotic bacterial community. In the surrounding seawater, these cells are free living and scarce and do not produce light. However, they are able to bioluminesce when they reach high concentrations, similar to in lab cultures or when they colonize the light organ of the squid.

Interestingly, the cell abundances of $V$. fischeri within the squid follow a circadian pattern. At night, $V$. fischeri are present at high concentrations $\left(10^{10}-10^{11}\right.$ cells $\left.\mathrm{ml}^{-1}\right)$ and emit a diffusible factor, also named an autoinducer (AI), associated with the production of light. At the end of the night, most of the bacterial cells are expulsed from the light organ, leading to a dramatic reduction in bacterial concentration and in the diffusible factor. During the day, the concentrations of $V$. fischeri that have not been expulsed are very low, the diffusible factor is not produced, and the squid do not bioluminesce. However, this remaining population of Vibrio grow steadily under favorable conditions within the squid throughout the day and again reach at night a cell abundance that is sufficient to produce bioluminescence. This bacteria-squid association constitutes a bacteriaanimal symbiosis. The squid relies on Vibrio's light to escape predators or hunt prey. In return, the squid provide host and nutrients to the Vibrio (Graf and Ruby, 1998).

Since the first observations in the 70s, this original system of bioluminescence regulation has been fully chemically and genetically described. The diffusible signal was identified in 1981 as an acyl-homoserine lactone (AHL) and described as 3-oxo-hexanoyl-homoserine lactone (3-oxo-C6HSL) (Eberhard et al., 1981). The genetic cluster involved in this phenomenon was then characterized as a bi-directionally transcribed operon with 8 genes, named $\operatorname{lux} A-E$, IuxG, IuxI and luxR. The LuxA and LuxB proteins are the two subunits of luciferase, the enzyme responsible for light production. The LuxC-D-E proteins are involved in the synthesis of the luciferase substrates, while LuxG is a flavin reductase. However, in quorum sensing research, most of the interest is focused on LuxI and LuxR proteins. LuxI is the AI synthase responsible for AIs production, while LuxR is the receptor of this diffusible signal. When the AIs reach a threshold concentration in the nearby environment of bacterial cells (reflecting the increase in cell abundances), they bind to the LuxR receptors, which act as transcription factors and activate the expression of all lux genes. The 
diffusible signal is designated an $\mathrm{AI}$ as it promotes its own production through the autoinduction of luxI (Engebrecht et al., 1983, Swartzman et al., 1990).

\section{LOW CELL DENSITY}

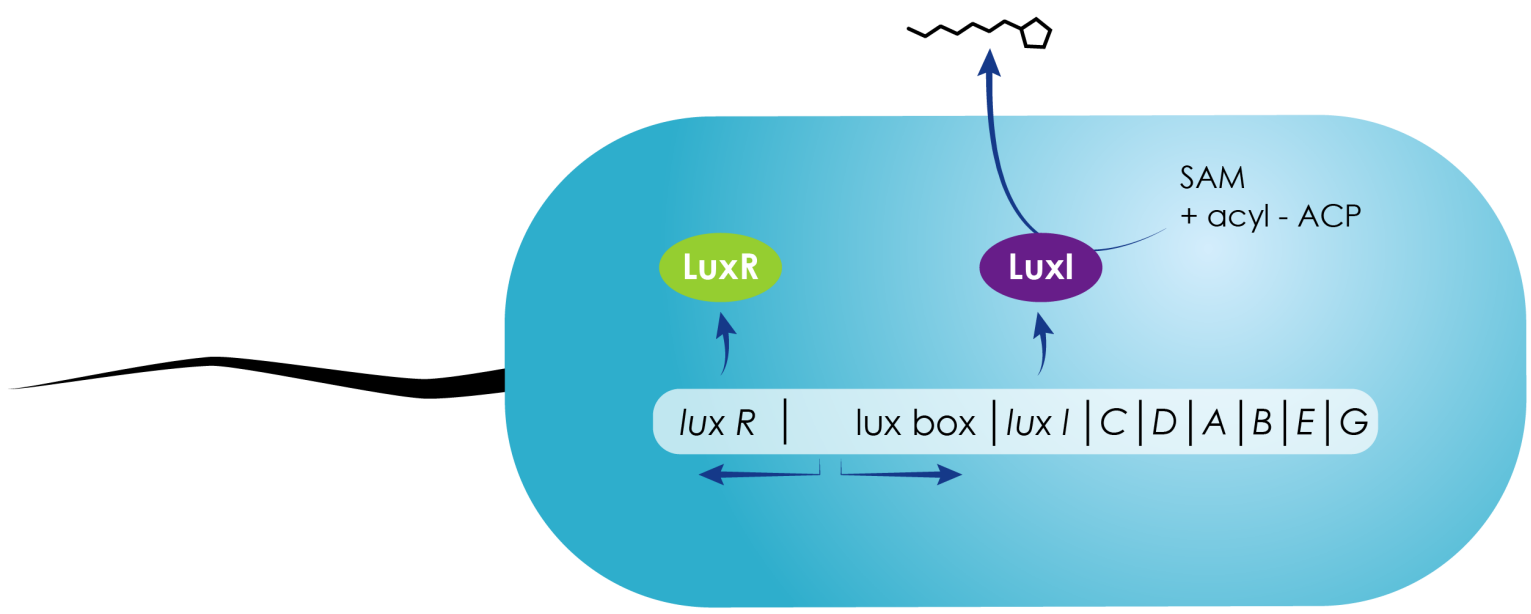

HIGH CELL DENSITY

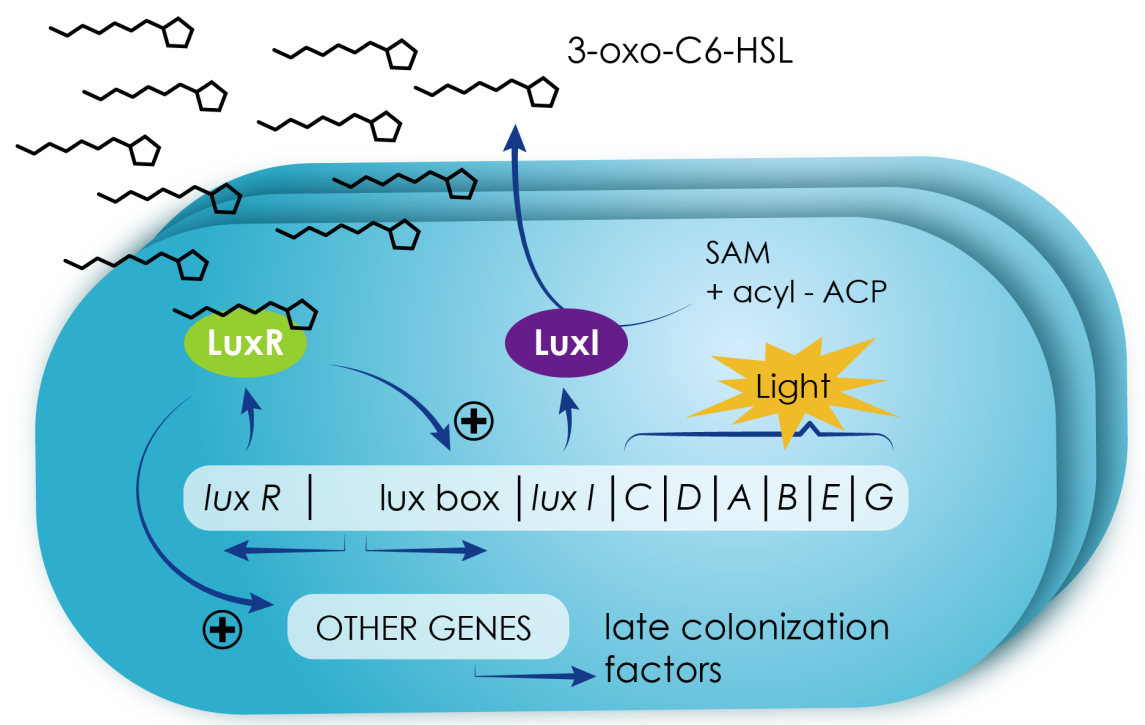

Figure 1 legend: A schematic representation of the first discovered luxI/luxR-based quorum sensing system in the model species Vibrio fischeri, producing 3-oxo-C6-HSL. Since then, a second quorum sensing system has been discovered. Based on the AinS AI synthase, it permits the liberation of C8-HSL.

\section{b. 1990-2010s: A growing interest in the study of quorum sensing in marine environments}

After these initial discoveries and subsequent full elucidation of the genetic system of quorum sensing, the study of this mechanism garnered little interest from the scientific community for more than a decade. Likely, quorum sensing appeared then to be a kind of regulation specialized for bioluminescence. This interest was renewed in the $90 \mathrm{~s}$ with the development of DNA sequencing methods and the discovery of a large diversity of luxI and luxR homologs in many 
different types of bacteria. Little by little, it appeared that the luxI-luxR model developed for $V$. fischeri was also relevant to a wide diversity of bacterial strains (Whiteley et al., 2017). These observations led to the establishment of the quorum sensing concept in 1994 (Fuqua et al., 1994).

However, despite the full characterization of the environmental Vibrio-squid model, most of the scientific effort in the field of quorum sensing was put forth in the 90 s and focused on strains with a medical or agronomic interest. Researchers devoted little attention to these mechanisms in the field of environmental sciences before 2005. An important reason for this interest in the medical field, among others, is that an increasing number of links were established during the 90 s between virulence and quorum sensing in pathogenic bacteria, such as in Staphylococcus strains (Ji et al., 1995) and Pseudomonas aeruginosa (Pearson et al., 2000). It was only in the following decade that work began to be published about bacteria in the field of environmental sciences, including those isolated from the marine waters. In 1998, one of the first reports of AIs present in the natural environment was published under the title "Quorum sensing autoinducers: do they play a role in natural environments?", which revealed some early interest in quorum sensing from the aquatic AIs in naturally occurring biofilms revealed (McLean et al., 1997). It was then hypothesized in 2001 that quorum sensing might function in marine particle-attached bacteria (Kiørboe, 2001). In 2002, Gram et al. reported for the first time the production of AHLs within Roseobacter and Marinobacter strains isolated from marine snow (Gram et al., 2002). Since then, a growing number of reports had focused on the nature and role of quorum sensing in marine bacteria, and large sets of culturedependent (Wagner-Dobler et al., 2005, Rasmussen et al., 2014) and culture-independent (Doberva et al., 2015, Muras et al., 2018a) studies have highlighted the importance of quorum sensing mechanisms in marine biofilms and environments.

\section{Overview of prokaryotic diversity and compounds involved in quorum sensing in marine environments and biofilms.}

\section{a. Experimental approaches to characterize autoinducers in the marine environment}

One important difficulty in characterizing AIs from the marine environment is their low concentration, which is at picomolar levels. Only in a few cases only have researchers been able to identify AIs directly on samples collected in situ, such as in marine snow (Jatt et al., 2015), phycosphere of phytoplankton cells (Bachofen and Schenk, 1998, Van Mooy et al., 2012) mucus covering cnidarians (Ransome et al., 2014), or microbial mats (Decho et al., 2009). However, such direct measurements of AIs concentrations remain rare, and indirect detection has generally been used, such as that described in the pioneering paper of Gram et al. (2002). In this workflow, the first step consists of the isolation of bacterial strains from the studied environment, such as a phytoplankton bloom (Bachofen and Schenk, 1998), algae cultures, microbial mats or marine snow (Gram et al., 2002, Wagner-Dobler et al., 2005, Schaefer et al., 2008). Then, the supernatant of the isolated cells is added to a culture of whole-cell biosensors, such as Escherichia coli JB523 (Andersen et al., 2001), Chromobacterium violaceum CV026 (McClean et al., 1997) or V. harveyi JMH612 (Henke and Bassler, 2004). These biosensors are very diverse and present large variation of sensibilities to detect various types of a (Steindler and Venturi, 2006). They are genetically modified organisms that are able to produce a signal in presence of the AIs eventually emitted in the supernatant of the screened strains. For example, $C$. violaceum produces the purple pigment violacein, and E. coli JB523 emits a GFP signal in presence of AHLs (Doberva et al., 2017).

The next step in quorum sensing compounds characterization relies on the tools used in the field of natural substances chemistry. Pioneering studies used thin-layer liquid chromatography (TLC) (Gram et al., 2002, Rivas et al., 2010). However, more recent approaches are usually based on liquid chromatography coupled with mass spectrometry (LC-MS) (Schaefer et al., 2008), gas chromatography coupled with MS (GC-MS) (Wagner-Dobler et al., 2005), and MS/MS approaches 
(Van Mooy et al., 2012). In some cases, these analyses are preceded by a microfractionation step, which allows a better separation and concentration of the extracted compounds (Doberva et al., 2017). When focusing on AHL characterization, the position of double bonds on the side chain of AHL can be determined by additional derivatization steps using dimethyl disulfide (Neumann et al., 2013). Definitive characterization can sometimes be achieved by 1D and 2D nuclear magnetic resonance (NMR) analyses depending on whether the purity and concentrations of targeted compounds are sufficient to allow such analyses.

\section{b. AHLs, or autoinducer-1 (AI-1)}

In marine environments, the production of AHLs is mostly due to Gram-negative bacteria and is found in many diverse types of marine Alpha-, Beta-, and Gammaproteobacteria. AI-1 is produced by LuxI family enzymes and detected by LuxR family receptors (Engebrecht et al., 1983). In addition, some AHLs are produced by ainS-like genes (Gilson et al., 1995) and in some cases by $h d t S$-like genes (Laue et al., 2000, Burton et al., 2005, Rivas et al., 2007). The AHLs are formed from $S$-adenosylmethionine and a fatty acid residue, which are the AIs synthases substrates (Moré et al., 1996, Schaefer et al., 1996, Parsek et al., 1999). Also, it has been evidenced some bacteria which harbor "LuxR orphans", meaning that these organisms are able to catch AHLs in the marine environment without producing them (Patankar and Gonzalez, 2009). Thus, they save the energetic cost of AHL production, but they are able to "sense" chemical dialogues in their nearby environment and adapt their physiology using such "spying" system. In addition, some "luxI orphans" have also been found in some marine bacterial genomes (Cude and Buchan, 2013). The ecological roles and importance of LuxI and LuxR orphans in marine waters remains to be studied.

AHLs are composed of a lactone ring attached to a fatty acid residue (the acyl side chain) with an amide bound. These AHLs present many types of structural variants that differ in length, with 4 to 19 carbons (Doberva et al., 2017) in the acyl side chain that can be saturated or unsaturated. These compounds also differ in the substitution that occurs at the C3 position (hydrogen, hydroxyl, or carbonyl group) and sometimes on other carbons in the acyl side chain. Additionally, a few AHLs with branched acyl side chains have been described, but to the best of our knowledge, not yet in marine strains (Thiel et al., 2009). Other authors have also reported AHLs presenting side chains with aromatic acid residues ( $p$-coumaric acid or cinnamic acid). This is the case of $p$-coumaroyl-HSL, which has been characterized in Rhodopseudomonas palustris but also discovered in the marine bacterium Silicibacter pomeroyi DSS-3 (Schaefer et al., 2008).

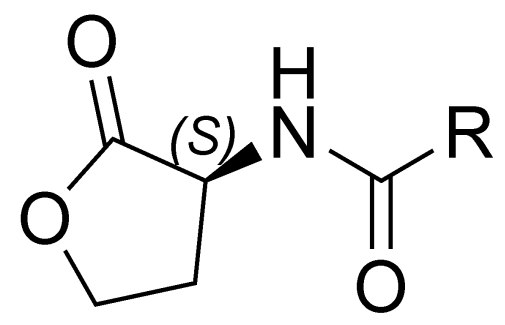

Figure 2 legend: The general chemical structure of AHLs. The lactone ring moiety is linked to a fatty acid residue (R) with an amide bound. The acyl side chain is highly variable in terms of length, oxidization state, and the presence hydrogen, hydroxyl or carbonyl groups; this variability provides to the AHL signal its specificity.

Most Rhodobacteraceae species (a major marine bacterial group involved in quorum sensing) produce long-chain AHLs with additional modifications (Cude and Buchan, 2013). The 
strain Rhodobacter sphaeroides, which is phylogenetically very closed to various marine strains (Béjà et al., 2002), synthesizes C14:1-HSL (Puskas et al., 1997). The marine Dinoroseobacter shibae emits C18:2-HSL, C18:1-HSL, and traces of C16-HSL, C15-HSL and C14-HSL (Wagner-Dobler et al., 2005, Neumann et al., 2013, Patzelt et al., 2013). The sponge symbiont Ruegeria sp. emits 3-OHC14-HSL, 3-OH-C14:1-HSL and 3-OH-C12-HSL (Zan et al., 2012). More recent papers using UHPLCHRMS/MS approaches have revealed a much broader diversity of AHL compounds in Rhodobacteraceae strains. The strain MOLA401 emits a large diversity of long-chain AHLs, with 20 different putative types of these compounds, including one with 19 carbons in the acyl side chain (Doberva et al., 2017). The strain Paracoccus sp. Ss63 from the sponge Sarcotragus emits long-chain AHLs, including 12 saturated and 4 unsaturated putative ones (Saurav et al., 2016b). Clearly, the real extent of AHLs diversity in marine Rhodobacteraceae strains remains an open question that still requires further investigations.

Phaeobacter sp. Y41<smiles>CC/C=C/CCCCCC(O)CC(=O)NC1CCOC1=O</smiles>

3-OH-C12:1-HSL

Phaeobacter inhibens<smiles>CC(O)CC(=O)NC1CCOC1=O</smiles>
3-OH-C10-HSL

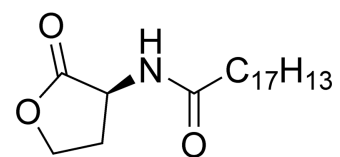

C18:1-HSL<smiles>CCCCCCCC(=O)NC1CCOC1=O</smiles>

C8-HSL

Ruegeria sp. KLH11<smiles>CC/C=C/CCCCCCCC(O)CC(=O)N[C@H]1CCOC1=O</smiles>

3-OH-C14:1-HSL<smiles>CCCCCCCCCC(O)CC(=O)N[C@H]1CCOC1=O</smiles>

3-OH-C12-HSL

Dinoroseobacter shibae

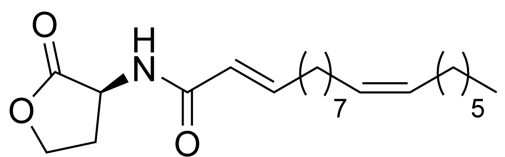

(2E,11Z)-N-Octadeca-2,11-dienoyl-HSL C18:2-HSL

Rhodobacter sphaeroides<smiles>CCCCCC/C=C/CCCCCC(=O)N[C@H]1CCOC1=O</smiles>

(Z)-N-Tetradec-7-enoyl-HSL C14:1-HSL

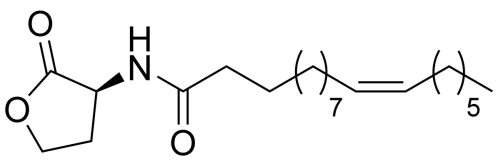

(Z)-N-Octadec-11-enoyl-HSL C18:1-HSL

Rhodopseudomonas palustris Ruegeria (Silicibacter) pomeroyi<smiles>O=C(/C=C/c1ccc(O)cc1)N[C@H]1CCOC1=O</smiles>

p-Coumaroyl-HSL

Figure 3 legend: A snapshot of AHL diversity in marine Rhodobacteraceae 
Vibrionaceae strains are found in many types of marine environments and hosts and are frequently pathogens of fishes, mollusks and corals (Vibrio anguillarum, Vibrio vulnificus $V$. harveyi...) or symbionts of squids (Aliivibrio fischeri, Vibrio pomeroyi, Vibrio aesturianus...). The first quorum sensing signal was discovered in the marine squid associated A. fischeri (see earlier in this chapter). Since this discovery, a few Vibrio have been fully described as prokaryotic models for the study of quorum sensing (Milton, 2006). Nevertheless, the extent of AHL signals diversity across Vibrio species is far from fully explored. The screening of Vibrio collections for AHL production has revealed contradictory data, with between 9 and 85\% of strains testing positive in these biotests (Garcia-Aljaro et al., 2012, Purohit et al., 2013, Girard et al., 2017), making difficult the determination of the real extent of AHL types distribution across this genus. Nevertheless, a few studies have attempted to characterize the chemical diversity of AHLs in diverse Vibrio strains. In general, the lengths of acyl side chains of AHL were found shorter than those detected in Rhodobacteraceae strains: C4-HSL to C12-HSL in diverse Vibrio strains (Purohit et al., 2013, Rasmussen et al., 2014) and C10-HSL to C14-HSL in Vibrio tasmaniensis LGP32 (Girard et al., 2017).

Vibrio fischeri<smiles>CCCC(=O)CC(=O)N[C@H]1CCOC1=O</smiles><smiles>[R]C(=O)N[C@@H]1CCOC1=O</smiles>

$\mathrm{R}=n-\mathrm{C}_{5} \mathrm{H}_{11}: \mathrm{C} 6-\mathrm{HSL}$

$\mathrm{R}=n-\mathrm{C}_{7} \mathrm{H}_{15}: \mathrm{C} 8-\mathrm{HSL}$

3-oxo-C6-HSL

Vibrio harveyi<smiles>CC(O)CC(=O)N[C@H]1CCOC1=O</smiles>

Vibrio salmonicida

3-hydroxy-C4-HSL<smiles>CCCCCCCCC(=O)N[C@H]1CCOC1=O</smiles>

C6-HSL<smiles>CCCC(=O)CC(=O)N[C@H]1CCOC1=O</smiles>

3-oxo-C6-HSL

Vibrio anguillarum<smiles>CCCCCCCCC(=O)N[C@H]1CCOC1=O</smiles>

C6-HSL<smiles>CCCC(O)CC(=O)N[C@H]1CCOC1=O</smiles>

3-hydroxy-C6-HSL<smiles>CCCCCCCCCCC(=O)CC(=O)N[C@H]1CCOC1=O</smiles>

3-oxo-C10-HSL

Vibrio vulnificus<smiles>CCCC(=O)N[C@H]1CCOC1=O</smiles>

C4-HSL

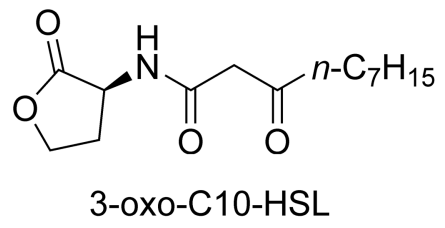<smiles>O=C(CC(=O)O[Na])N[C@H]1CCOC1=O</smiles>

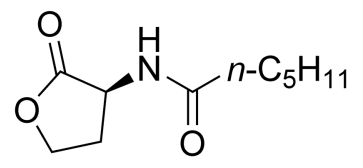

C6-HSL<smiles>CCCCCCCCCCCC(=O)N[C@@H]1CCOC1=O</smiles>

3-oxo-C14-HSL

Figure 4 legend: A snapshot of AHL diversity in marine Vibrionaceae 
An AHL-based quorum sensing system has also been found in some marine Mesorhizobium (Krick et al., 2007), Bacteroidetes (Huang et al., 2008, Romero et al., 2010) and Cyanobacteria (Sharif et al., 2008, Romero et al., 2011b). Additionally, some evidence of AHL production has been detected in aquatic Archaea (Paggi et al., 2003, Montgomery et al., 2013), as well as in the marine Gram-positive bacteria, Exiguobacterium (Biswa and Doble, 2013). By contrast, some important groups of marine bacteria do not appear to produce AHLs, such as members of the SAR11 group, which dominates many types marine prokaryotic communities (R. Lami, unpublished data based on biosensors P. putida F117 and E. Coli MT102 ).

\section{c. Autoinducer-2 (AI-2)}

4,5-Dihydroxy-2,3-pentanedione (DPD) is the precursor of AI-2 and is synthesized by the LuxS enzyme. The enzyme LuxS, which converts $S$-ribosyl homocysteine to homocysteine and DPD, catalyzes the key step in AI-2 biosynthesis (Schauder et al., 2001). The AI-2 are is found in many different types of both Gram-negative and Gram-positive bacteria, thus, this AI may serve as an interspecies signal (Surette et al., 1999, Xavier and Bassler, 2005). In the presence of boron, DPD leads to $(2 \mathrm{~S}, 4 \mathrm{~S})-2$ methyl-2,3,3,4-tetrahydroxytetrahydrofuran-borate (S-THMF-borate). In the marine environment, this compound is used as AI-2 in Vibrio (Chen et al., 2002). In the absence of boron, DPD leads to (2R,4S)-2-methyl-2,3,3,4-tetrahydroxytetrahydrofuran (R-THMF), which is the AI-2 signaling compound in enteric bacteria (Miller et al., 2004). The presence or absence of borate in local environments may shift the spontaneous non-enzymatic rearrangements between the two known forms of AI-2. (Miller et al., 2004). However, some researchers have raised doubt about the signaling function of AI-2, as DPD is also a side product of the activated methyl cycle (De Keersmaecker et al., 2006, Rezzonico and Duffy, 2008).

The presence of DPD in the marine environment has been confirmed by direct measurements in natural samples (Van Mooy et al., 2012). AI-2 signaling is frequently utilized by Vibrio species (Milton, 2006), as confirmed by culture-based studies (Yang et al., 2011). The examination of the phylogenetic diversity of luxS-translated sequences in the Global Ocean Sampling database suggests that Shewanella-related species constitute a major group using AI-2 signaling in marine environments (Doberva et al., 2015), as also observed among cultivated strains (Bodor et al., 2008). Sulfurovum lithotrophicum and Caminibacter mediatlanticus are Epsilonproteobacteria that grow within biofilms colonizing deep-sea hydrothermal environments. These bacterial strains were found to express AI-2-based quorum sensing, and luxS transcripts were also found directly from RNA extracts and subsequent RT-qPCR performed on deep sea biofilms (Perez-Rodriguez et al., 2015). Despite these few studies, the real extent of bacterial diversity involved in AI-2 signaling as well as the ecological role of this AI require further investigation.

\section{d. Other autoinducers}

In marine environments, $V$. harveyi synthesizes the AI (Z)-3-aminoundec-2-en-4-one. In fact, a chemically very similar compound was first discovered in Vibrio cholerae, which synthesizes $(S)$ 3-hydroxytriecan-4-one, which gives the name to this family of AIs: CAI-1 or Cholera AI-1. The enzyme that synthesizes CAI-1 belongs to the CqsA-family, which is found in all Vibrio. Whether CAI-1 plays an ecological role in natural marine communities remains to be evaluated in future experiments (Higgins et al., 2007, Kelly et al., 2009, Ng et al., 2011, Wei et al., 2011).

There are many others AIs that were discovered in marine strains and for which little data have yet been published. 3,5-Dimethylpyrazin-2-ol (DPO) has been demonstrated to be an AI in $V$. cholerae, activating the expression of vqmR, encoding small regulatory RNAs (Papenfort et al., 2017). In addition, tropodithietic acid (TDA) has been described as an AI in Rhodobacteraceae (Geng and Belas, 2010). Collectively, these observations clearly reveal that quorum sensing AIs are 
not limited to AI-1 and AI-2 families in the marine environment. There is probably a much broader diversity of quorum sensing semiochemicals that remain to be discovered and probably play important ecological roles in association with the dynamics of marine microbial communities.

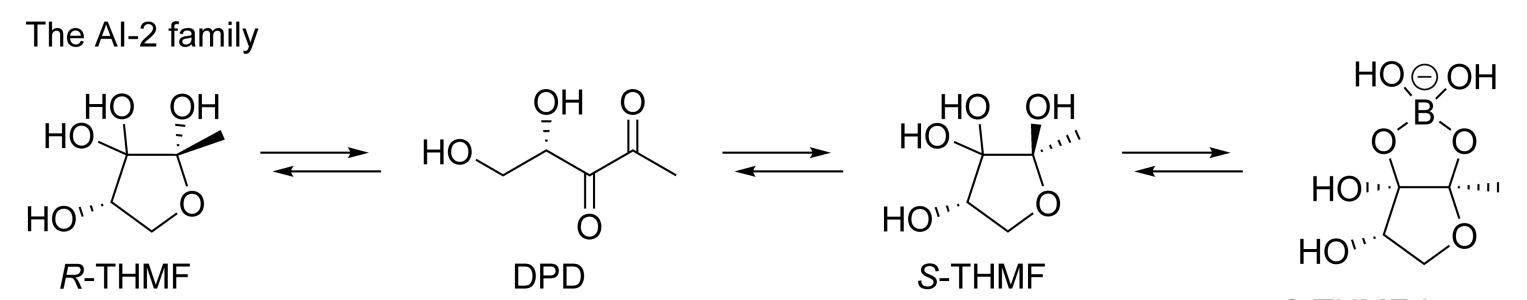<smiles>CCCCCCCCCC(=O)[C@H](O)CC</smiles>

CAl-1<smiles>C/C=C(\N)C(=O)CCCCCCC</smiles>

Ea-8-CAl-1

Tropodithietic acid (TDA)

3,5-Dimethyl-pyrazin-2-ol (DPO)<smiles>O=C(O)c1c(=O)cccc2ssc12</smiles><smiles>Cc1cnc(O)c(C)n1</smiles>

Figure 5 legend: The AI-2 and CAI-1 autoinducer families and the structure of the autoinducers TDA and DPO

\section{e. Diffusion of autoinducers in the marine environment.}

Once produced by marine bacteria, AIs passively diffuse through the marine environment to reach their target. It appears that the signaling compounds cannot diffuse over "calling distances" longer than 10-100 $\mu \mathrm{m}$ (Gantner et al., 2006), in accordance with their thermodynamic and chemical characteristics, like solubility, diffusivity, dispersion potential or chemical stability (Harder et al., 2014). According to Fick's law, short-chain AHLs will diffuse more rapidly than longchain AHLs. The molecular weight of AHLs and their solubility are negatively correlated with their mobility, but other characteristics modify this general rule. On one hand, the presence of hydroxyor oxo-substitutions along their acyl side chain can increase their solubility and thus their capacity to passively diffuse. On the other hand, long-chain AHLs with high molecular weight are also predicted to adsorb to organic surfaces (Decho et al., 2011, Harder et al., 2014).

Many other factors must be considered to differentiate AHL diffusion processes from one bacterium to another one. Abiotic processes can lead to a rapid base hydrolysis of the lactone ring, especially under alkaline conditions; and converts AHLs in inactive $\gamma$-hydroxy carboxylates. However, this process is reversible under acidic conditions (Yates et al., 2002, Delalande et al., 2005, Tait et al., 2005). Additionally, it is worth noting that AHLs that present an oxo-substitution on their 3-carbon can be subjected to a spontaneous Claisen condensation, forming tetramic acids, which inhibits their capacity to transmit information (Kaufmann et al., 2005). The half-life of 3-oxoC6-HSL has been established in days according to the following formula: $1 /\left(1 \times 10^{7} *\left[\mathrm{OH}^{-}\right]\right)$ (Schaefer et al., 2000). However, much slower degradation rates of 3-oxo-C6-HSL have been experimentally reported in artificial marine waters $\left(0.094 \mathrm{~h}^{-1}\right.$ versus $0.26 \mathrm{~h}^{-1}$ according to the 
formula), suggesting that AHLs can diffuse over longer distances than initially hypothesized (Hmelo and Van Mooy, 2009). In the same report, slower degradation rates than those previously published for unsubstituted AHLs were also reported. Additionally, a few reports have noted that short-chain AHLs present shorter half-lives than those of long-chain AHLs, suggesting that long-chain AHLs might diffuse over longer distances than do short-chain AHLs (Decho et al., 2011).

AHL diffusion can be limited not only by the effects of abiotic factors but also by those of biotic factors. For example, it is well known that many bacteria or eukaryotes emit quorum quenching enzymes or chemical compounds that can degrade affect AIs diffusion and reception. Hmelo et al. (2009) reported that C6-HSL, 3-oxo-C6-HSL and 3-oxo-C8-HSL have degradation rates that are respectively 54, 23 and 57\% higher in natural seawater than in artificial seawater, and these authors attributed this increase to the occurrence of quorum quenching processes in the marine waters, for which more details are provided in the last section of this chapter.

Overall, the diffusion through marine environments of AHLs appears to be a complex phenomenon that is dependent of many diverse abiotic and biotic variables. One important last factor to consider is that these infochemicals are usually released in complex tridimensional biofilms, made of complex exopolymers given density and thickness to these biological architectures (Harder et al., 2014). Thus, some authors tend to consider the chromatographic movement rather than the passive diffusion movement as the best concept to model the travel of AHLs through marine microniches (Decho et al., 2011). The architecture of biofilms can also provoke the sequestration AHLs in microniches, leading to locally important concentrations of AIs which can activate quorum sensing processes, even with few cells in the local environment (Charlton et al., 2000, Whiteley et al., 2017).

\section{f. Vibrio harveyi , a model for the study of quorum sensing in marine bacteria}

$V$. harveyi is a major pathogen in the marine environment and is responsible for many diseases observed in farmed oysters, mollusks and shrimps, leading to substantial economic loss (Austin and Zhang, 2006). V. harveyi possesses a complex quorum sensing system with three interdependent channels: AI-1, AI-2 and CAI-1 AI-based quorum sensing (Henke and Bassler, 2004). In all cases, AIs bind to their cognate membrane receptors and thus activate an intracellular phosphorylation/dephosphorylation signal transduction cascade. The key protein in this transduction cascade is LuxO, a response regulator which integrates the signals from the 3 channels presenting various levels of phosphorylation (Lilley and Bassler, 2000). At low cell densities, when phosphorylated, LuxO activates through five quorum regulatory sRNAs (Qrr RNAs) the protein AphA which regulates many genes, in particular those involved in the expression of most of the identified virulence factors as well as biofilm formation (see below in this chapter for detailed discussion).

At low cell densities, Qrr RNAs inhibit the transcription of the master regulator LuxR (Lenz et al., 2004). However, when high concentrations of quorum sensing signals are present, LuxO is dephosphorylated and the expression of lux genes is induced. More precisely, the concentration of LuxR in the cytoplasm is dependent on the concentrations of these 5 different types of small regulatory RNAs, which are correlated with the level of phosphorylation of LuxO. At such high cell densities, the production of AphA is inhibited and LuxR dependent genes are activated, like those involved in bioluminescence production.

In the section 4 of this chapter, we'll review the diversity of quorum sensing dependent phenotypes and functions regulated by quorum sensing. One important fact to keep in mind is this opposition between the quorum sensing master regulator AphA, which coordinates low cell densities behaviors, and the quorum sensing master regulator LuxR, which controls high cell densities behaviors. In this sense, the regulation $V$. harveyi quorum sensing dependent phenotypes is complex. For example, among the virulence factors, quorum sensing positively regulates 
metalloproteases and extracellular toxins at high cell densities. By contrast, at such high cell densities, quorum sensing negatively regulates chitinases, phospholipases, siderophores, and type III secretion system. Such opposition probably reflects the need of different types of virulence factors at the different stages of infection (Natrah et al., 2011b).

LOW CELL DENSITIES

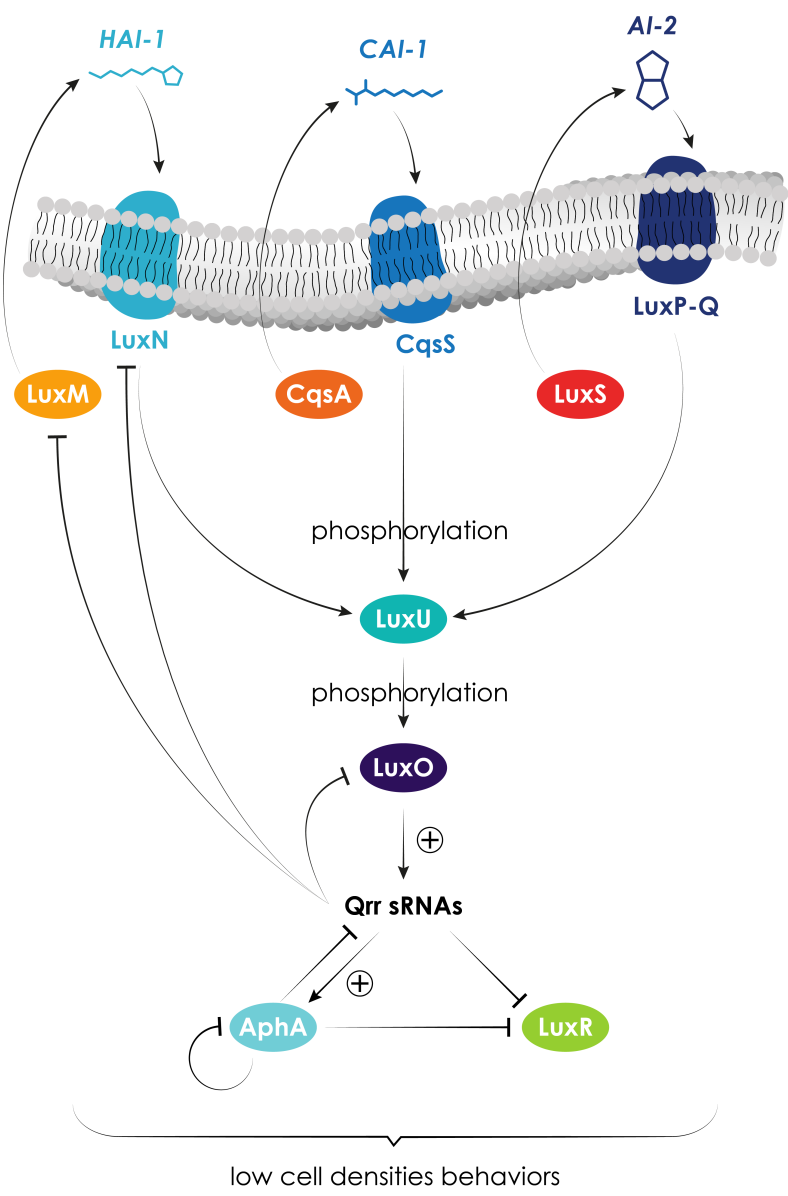

HIGH CELL DENSITIES

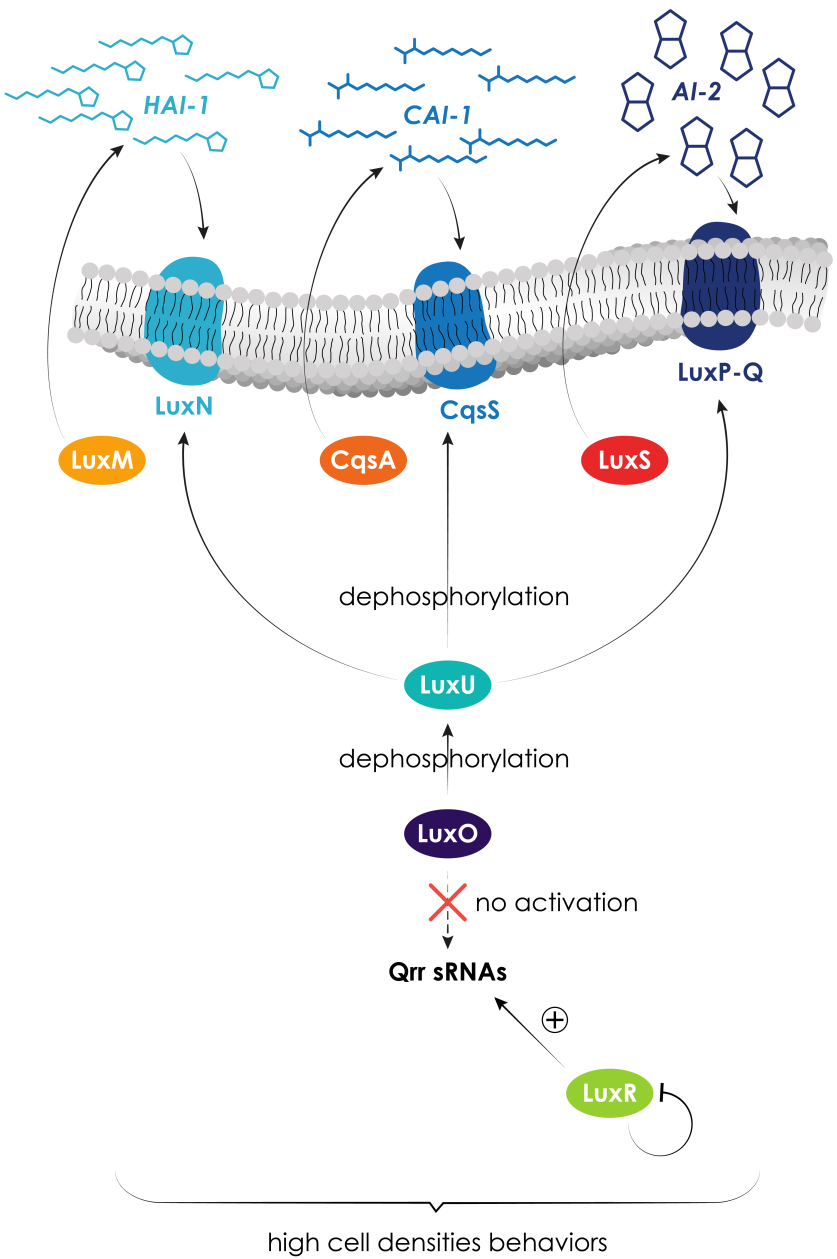

Figure 6 legend: Quorum sensing signaling pathways in the model marine strain $V$. harveyi and their mode of functioning at low and high cell densities.

\section{Surface biofilms and holobionts: the diversity of microbial habitats enabling quorum sensing in the marine environment}

Quorum sensing occurs at high bacterial cell concentrations. Thus, it appears unlikely that free-living marine bacterial cells will perform quorum sensing. However, there are many (micro)niches and habitats in the marine environment where bacterial cells are organized in highly structured biofilms, where they reach sufficient abundances to induce quorum sensing-based dialogues. The biofilms are organized in a gel-like exo-macropolymeric matrix, a three-dimensional architecture that includes a micrometer-scale spatial organization and efficiently concentrates chemical compounds (McLean et al., 1997, Decho et al., 2011). Also, prokaryotes colonize marine plants, vertebrates and invertebrates, and the recognition of such importance of the bacterial microbiota for other organisms lead to the concept of holobiont. Again, an holobiont provides 
possible bacterial concentrations and the occurrence of prokaryotic interactions, including quorum sensing (Teplitski et al., 2016). Some examples will be described in this section.

\section{a. Phycosphere of (micro)-algae and phyllosphere of marine plants}

The phycosphere corresponds to the immediate region surrounding algae. It describes a microbial habitat that is deeply shaped by algae (Bell and Mitchell, 1972). In this microenvironment, bacterial abundances can reach $10^{8}-10^{11}$ cells per ml (Paerl, 1982, Sheridan et al., 2002), enabling the occurrence of quorum sensing. The pioneering study published by Bachofen and Shenk in 1998 revealed the production of AHLs within a cyanobacterial phytoplankton bloom in concentrations that can reach $10 \mathrm{mg} \mathrm{l}^{-1}$ (Bachofen and Schenk, 1998, Schaefer et al., 2008). Since then, many reports about quorum sensing processes in the phycosphere of (micro)algae have been published (Rolland et al., 2016). A recent experiment using transcriptomics approaches noted an increase in luxI and luxR gene expression within Ruegeria pomeroyi co-cultured with the microalgae Alexandrium tamarense. This work revealed putative important links between microalgae growth and quorum sensing-dependent physiological regulations within Rhodobacteraceae strains associated to some microalgae (Landa et al., 2017).

Many strains capable of quorum sensing were isolated from the phycosphere of micro- and macro-algae, and the compounds that they produce and their involvement in cell-to-cell signaling were elucidated. For example, strains affiliated with different species isolated in diverse phycospheres were revealed as AHL producers, such as D. shibae, Hoeflea phototrophica, and Roseovarius mucosus producing C18:1-HSL and C14:1-HSL (Wagner-Dobler et al., 2005). Some authors have also reported the capacity of cyanobacteria to produce AHLs, particularly the toxin producer Microcystis aeruginosa (Zhai et al., 2012) as well as the epilithic Gloeothece PCC6909 (Sharif et al., 2008) that emits C8-HSL.

There are not only AHLs that are involved in quorum sensing signaling within the phycosphere but also a large diversity of compounds, of which many fewer observations have been made. For example, few AI-2 producers were isolated from the phycosphere of phytoplankton. However, recent reports noted some Vibrio that were isolated in the phycosphere of Trichodesmium and were able to produce this AI (Van Mooy et al., 2012). A potential role for AI-2 in the control of the algaecide activity against the dinoflagellate Gymnodinium catenatum has also been hypothesized (Skerratt et al., 2002). TDA has been characterized as an AI in many Rhodobacterales species (Geng and Belas, 2010) and is frequently associated with microalgae, similar to the bacterial strains affiliated with the genera Phaeobacter, Silicibacter, and Ruegeria (Brinkhoff et al., 2004, Bruhn et al., 2005, Geng et al., 2008, Porsby et al., 2008).

In a recent paper, our group investigated the prevalence of quorum sensing in the microbiota associated with marine plants. We selected the Mediterranean seagrass Posidonia oceanica, a marine angiosperm that plays a key role in coastal ecology. To address this question, we isolated 60 strains from Posidonia oceanica leaves and rhizomes, including epiphytic and endophytic strains. From this collection, we were able to detect 6 strains able to emit 8 different types of AHLs and 19 strains able to activate the AI-2 biosensors. These results reveal the importance of examining quorum sensing relationships also within the microbiota of marine angiosperms to better understand the complex relationships that may exist between these microbes and their host (Blanchet et al., 2017).

\section{b. Biofilm around sinking marine snow particles}

Marine snow includes particles that are larger than $0.5 \mathrm{~mm}$ and are sinking in the deep ocean. These aggregates, which are composed of organic and inorganic carbon, have been recognized to play a major role in the oceanic and global carbon cycles (Fowler and Knauer, 1986). Important consortia of marine bacteria colonize marine snow (Ploug et al., 1999, Simon et al., 
2002), and their metabolic activities largely contribute to shape the composition of these aggregates. For example, these communities express large sets of hydrolytic enzymes that are involved in the degradation of particulate organic carbon (Smith et al., 1992). These bacterial consortia are structured in a biofilm, and marine snow constitutes hotspots of high bacterial concentrations in the oceans, with $10^{8}$ to $10^{9}$ cells per ml, which are 2 to 4 orders of magnitude compared with the ambient seawater (Ploug et al., 1999, Simon et al., 2002).

A first report in 2002 by Gram et al. revealed the production of AHLs among 4 of 43 bacterial strains isolated from marine snow. They highlighted in these strains the production of C6-HSL and C8-HSL (Gram et al., 2002), and identified them as affiliated with the genera Roseobacter and Marinobacter. This pioneering study revealed that quorum sensing regulations occur in particleattached marine microbial communities. This paper then hypothesized that quorum sensing might regulate bacterial hydrolytic enzymes activities, biofilm formation or antibiotic production in such marine niches. Other interesting pieces of information were then published by Hmelo et al. in 2011. In this study, the authors were able to detect AHLs directly on aggregates collected from the Pacific Ocean near Vancouver Island. Additionally, they were able to prove that the addition of exogenous AHLs into flasks containing sinking marine snow aggregates increased the activity of bacterial hydrolytic enzymes (Hmelo et al., 2011). In a similar approach, Jatt et al. in 2015 were also able to detect in situ the production of AHLs, and revealed the presence of 3-oxo-C6-HSL and C8-HSL in marine snow aggregates collected from China's marginal seas. Among diverse isolates which were detected as AHLs producers, the authors also reported the isolation of a marine strain affiliated with the species Pantoea ananatis able to produce 6 different types of AHLs. In their experiments, they revealed that the addition of exogenous AHLs to the culture media increased the extracellular hydrolytic enzymes activities. In particular, they noticed an upregulation of alkaline phosphatases activities (Jatt et al., 2015). Collectively, these data reveal that quorum sensing might play a crucial role in the regulation of the activities of bacteria colonizing marine snow. In this sense, quorum sensing might be a crucial process regulating the carbon cycle in the ocean; many more studies coupled with in situ measurements are required to support this hypothesis.

\section{c. Marine microbial mats and other types of subtidal biofilms}

Very little work has been conducted about quorum sensing in marine microbial mats and diverse types of subtidal biofilms. These biofilms are one of the earliest forms of life known on Earth (3.4-3.5 Gy bp) and have been identified in fossils such as stromatolites (Shen et al., 2001, Tice and Lowe, 2004, Allwood et al., 2006, Canfield, 2006). These microbial mats are highly diverse in terms of microbial community composition and functions and are organized in very well structured, layered assemblages (Ley et al., 2006, Feazel et al., 2008). Thus, they present important cell abundances that are fully compatible with the occurrence of quorum sensing regulations.

The pioneering study published by McLean et al. in 1997 was the first report of AHLs in natural environments and focused on submerged biofilms. While this study did not focus on marine biofilms, it provided a lot of interesting data for aquatic environments. These researchers revealed the absence of AHLs on rocks not coated with natural biofilms and their presence on those covered with biofilms (McLean et al., 1997). A few years later, a report published by Decho et al. revealed very interesting patterns of AHLs regulation in marine mats. First, they were able to collect and characterize AHLs directly on marine mat samples collected in situ and detected both long- and short-chain AHLs (C4- C6- oxo-C6-, C7-, C8-, oxo-C8-, C10-, C12- and C14-HSLs). Even more interestingly, the authors revealed that short-chain AHLs were significantly less present during the day. One possible interpretation is that diel variations in $\mathrm{pH}$ may alter short-chain AHLs when $\mathrm{pH}$ is above 8.2 during the day, due to photosynthetic processes (Decho et al., 2009). The development of subtidal biofilms appears to be very dynamic, and it has been shown that with the variation in community composition, the pattern of emitted AHLs is also modified. Many AHLs producers were 
isolated in such biofilms (Huang et al., 2008). In particular, AHL-producing Vibrio spp. appear be pioneer species in these biofilms (Huang et al., 2009).

Many studies have demonstrated that the presence of a bacterial biofilm favors the settlement on surfaces of invertebrate larvae. In particular, a series of interesting papers have highlighted that the AHLs produced in marine biofilms are detected by diverse types of larger organisms to guide their settlement (Wieczorek and Todd, 1998, Hadfield and Paul, 2001, Hadfield, 2011). Among the chemical attractants, AHLs were found to play an important role for the zoospores of the macroalga Ulva. The detection of AHLs by these spores leads to a modification of their swimming behavior and the provocation of chemokinesis, which favor their settlement on the biofilm. These data revealed that AHLs produced in bacterial biofilms can also be sensed by eukaryotes, and these studies pointed out that AHLs also act as inter-kingdom chemical signals (Joint et al., 2002, Tait et al., 2005). In a similar vein, it has been shown that AHLs favor the settlement of cyprid larvae of Balanus improvisus in bacterial biofilms (Tait and Havenhand, 2013)

\section{d. Corals and other cnidarian-associated communities}

Many cnidarians species harbor bacterial-associated communities in which members communicate using quorum sensing signals. For example, Anemonia viridis and the Gorgonacea Eunicella verrucosa harbor very diverse associated bacterial communities including quorum sensing AIs producers (Ransome et al., 2014). However, most of the work on cnidarian species in the field of quorum sensing has focused on corals, especially in the context of pathogenicity (i.e., black band disease, white band disease, etc.).

Coral species harbors important and dense associated microbial communities that are 101000 fold more concentrated compared to the ambient seawater (Rosenberg et al., 2007). A study conducted in 2011 reports that $30 \%$ of bacteria in these consortia are capable of quorum sensing. These include a Vibrio strain that has been shown to emit 3-OH-C10-HSL detected using TLC (Golberg et al., 2011). Similarly, in another study published in 2010, a total of 29 Vibrio isolates were collected in different healthy or diseased corals (samples collected from mucus, tissues, surrounding waters) and were tested for their ability to produce quorum sensing compounds (Tait et al., 2010). The authors found that all isolated Vibrio were able to emit AI-2, and 17 were found capable of AHL synthesis, including strains isolated from both healthy and diseased animals (Tait et al., 2010). Interestingly, in the same study, the authors reported that temperature can inhibit AHL production in the pathogen $V$. harveyi (Tait et al., 2010). Collectively, these data suggest that quorum sensing may play a role in coral diseases and Vibrio infections, but the potential mechanisms behind this hypothesis remain to be elucidated (Milton, 2006, Hmelo et al., 2011, Kimes et al., 2012).

More pieces of information have recently come from researchers studying the white and black band diseases, which are polymicrobial illnesses threatening corals. Some strains capable of quorum sensing were isolated within the bacterial consortia responsible for the coral affections (Zimmer et al., 2014). Interestingly, it was then shown that the exposure of Acropora cervicornis to C6-HSL converts its healthy microbiome into one responsible for white band disease (Meyer et al., 2016). Moreover, the addition of quorum sensing-inhibiting compounds dramatically modified the composition of the infected coral microbiota, as revealed by 16SrRNA gene sequencing (Certner and Vollmer, 2015). Also, the inoculation of Aiptasia pallida to coral commensals presenting a quorum quenching activity inhibited the capacity of Serratia marescens to degrade polyps (Alagely et al., 2011). Similarly, Meyer et al. in 2016 studied the black band disease and pointed the production by associated cyanobacteria of lyngbic acid, a strong anti-quorum sensing compound that can selectively inhibit cell-to-cell communication in some bacterial species (Meyer et al., 2016). Collectively, these results acquired from studying two different coral diseases underline the 
importance of quorum sensing in the regulation of coral-associated microbiota in either healthy or diseased animals (Hmelo et al., 2011, Teplitski et al., 2016).

\section{e. Sponge-associated communities}

The sponge (phylum Porifera) microbiome is complex and diverse (Reveillaud et al., 2014, Webster and Thomas, 2016). It has been found that some sponges are poorly colonized by bacteria, while some other are not (Hentschel et al., 2003). However, bacteria colonizing sponge tissues can represent up to 35\% of the sponge biomass (Vacelet and Donadey, 1977). Again, in this type of micro-niche, bacteria can frequently reach a sufficient abundance to establish a quorum sensingbased communication, and diverse sponge symbionts able to produce AIs are found (Taylor et al., 2004, Mohamed et al., 2008). Additionally, some reports suggest that this type of communication between sponge bacterial symbionts is frequent, as $77 \%$ of studied Australian sponges are able to activate AHL-based biosensors (Taylor et al., 2004), and 46\% of sponge species are from the Mediterranean and Red Sea (Britstein et al., 2017).The chemical diversity of AHLs involved in these microbiota has been elucidated and was found to be very diverse, including short and long acyl side chains and between 6 and 18 carbons (Saurav et al., 2017). For example, C6-HSL, C7-HSL and 3-oxoC12-HSL were detected in the Celtic sea sponge Suberites domuncula (Gardères et al., 2012), and an increasing number of AHLs from sponges are now being characterized (Britstein et al., 2016, Bose et al., 2017). The strain Ruegeria sp. KLH11, isolated from Mycale laxissima, has been developed as a model to better understand the cellular effects of quorum sensing and to better characterize the relationship between quorum sensing expression and the traits of the bacterial sponge symbionts. These studies revealed the presence of two pairs of quorum sensing luxI/R genes and an orphan luxI gene that control biofilm formation (negatively regulated) and flagella-based motility (positively regulated) in this KLH11 strain model (Zan et al., 2011, Zan et al., 2013, Zan et al., 2015). Such regulation might limit the bacterial aggregation within the sponge, and favor its dispersion and release in the environment. Quorum sensing-dependent relationships between sponges and their symbionts appear to be very complex. For example, bacterial 3-oxo-C12-HSL modifies gene expression in $S$. domuncula and inhibits its innate immune system (Gardères et al., 2014), and some sponge compounds are able to interfere with quorum sensing signaling (Costantino et al., 2017).

\section{Diversity of prokaryotic functions regulated by quorum sensing in marine environments a. Bioluminescence and pigment production}

Pioneering papers about quorum sensing described the details of bioluminescence regulation in the historical model $V$. fischeri. These details and references are provided to the reader in the first section of this chapter, and here is a reminder that bioluminescence is an important marine bacterial trait regulated by quorum sensing.

Pigment production (and in particular the purple violacein) is known to be regulated by quorum sensing (McClean et al., 1997). In the marine environment, a quorum sensing dependent production of violacein has been reported in the marine strain Pseudoalteromonas ulvae TC14 (Ayé et al., 2015). Interestingly, in planktonic conditions, the strain do not appears to produced AHLs, nevertheless the production of violacein is upregulated by the addition of C6-, C12-, 3-oxo-C8-, and 3-oxo-C12-HSL and downregulated by 3-oxo-C6-HSL. In sessile conditions, the 3-oxo-C8 was found to upregulate the emission of the purple pigment. Collectively, these results suggest that violacein production in this strain is regulated through an orphan LuxR receptor.

\section{b. Motility}

In the initial stages of colonization, or at low or average cell densities, motility is frequently activated by quorum sensing. For example, motility has been found upregulated in the $V$. fischeri colonizing the squid E. scolopes (Lupp et al., 2003, Lupp and Ruby, 2005). The AphA quorum 
sensing master regulator is involved in low cell densities motility behaviors, like in $V$. alginolyticus (Gu et al., 2016) and V. parahaemolyticus (Wang et al., 2013). Similar results were observed with $V$. harveyi (van Kessel et al., 2013). However, in V. cholerae, the upregulation of motility is indirectly controlled by quorum sensing and depends on the intracellular c-di-GMP pool (Rutherford et al., 2011). At high cell densities, the master regulators LuxR/HapR are also able to control motility in some Vibrio species, like in the marine pathogen V. vulnificus (Lee et al., 2007). By contrast, OpaR negatively regulates motility in V. parahaemolyticus and V. fischeri (Lupp and Ruby, 2005). Interestingly, LuxR also activates motility in $V$. cholerae at high cell densities, probably to promote cell detachment and biofilm dispersion (Reidl and Klose, 2002).

\section{c. Initiation of biofilm formation, maturation and dispersion}

Pioneer studies in the medical field revealed a positive relationship between quorum sensing expression and biofilm formation (Davies et al., 1998). However, the relationship between biofilm formation and emission of quorum sensing compounds is more complex. For example, among Rhodobacteraceae, Silicibacter lacuscaerulensis and S. pomeroyi have quorum sensing genes, but they do not have the same capacities for surface colonization (Slightom and Buchan, 2009). One possible explanation for such complexity is that biofilm formation, maturation and dispersion rely on diverse and multiple steps that are under the control of multiple regulatory and signaling pathways that are frequently interconnected and can act differently before being integrated at the cellular level. The in-depth genetic analysis conducted on the aquatic pathogens $V$. cholerae and $V$. harveyi sheds light on such complexity. In these cells, the sensory transduction pathways of quorum sensing, chemotaxis, and two-components signaling are connected to each other and to the c-diGMP intracellular pool, as well as small RNA-mediating signaling pathways. In these strains, it has been experimentally demonstrated that this network of signaling pathways is associated with biofilm formation (Tu and Bassler, 2007, Monds and 0'Toole, 2009, Svenningsen et al., 2009, Srivastava et al., 2011, Srivastava and Waters, 2012, Hunter and Keener, 2014).

Another layer of explanation is that biofilm formation, surface attachment, biofilm maturation and dispersion require different types of regulation according to the life strategies of bacteria. Quorum sensing has been found to be involved in surface attachment in Serratia marcescens (Labbate et al., 2007), an opportunist pathogen that can sometimes be found in marine environments (Alagely et al., 2011). In some Vibrios species, at low cell densities, the AphA master regulator also controls biofilm formation. This has been observed in V. cholerae. (Yang et al., 2010), V. parahaemolyticus (Wang et al., 2013), V. alginolyticus (Gu et al., 2016).

At high cell densities, quorum sensing LuxR-type proteins repress biofilm production in $V$. cholerae (Waters et al., 2008). However, the opposite pattern is observed in V. parahaemolyticus and V. vulnificus (Lee et al., 2007, Yildiz and Visick, 2009), and V. anguillarum (Croxatto et al., 2002). Many bacteria also positively regulate biofilm production and maturation with quorum sensing. This is the case in the genus Aeromonas (Lynch et al., 2002), which includes fish pathogens. In maturating biofilms, other functions are activated by quorum sensing, such as the production of antimicrobial compounds or the maintenance of cell shape heterogeneity (see later in this chapter).

The dispersion of biofilm is also under the control of quorum sensing in many marine bacteria. In the sponge symbiont Ruegeria sp. KLH11 (Zan et al., 2012), cell motility is activated by quorum sensing and favors dissemination. At the same time, biofilm production is inhibited by quorum sensing at high cell densities, which probably also favor the dispersion of Ruegeria sp. KLH11 cells from its host (Zan et al., 2012). This is also probably why biofilm production is negatively regulated at high cell densities in the pathogen V. cholerae (Zhu and Mekalanos, 2003). Production of hydrolases may favors such dynamics. It has been demonstrated that the expression of some of these enzymes is positively regulated by quorum sensing, like in P. ananatis (Jatt et al., 2015). 
Collectively, these data emphasize the roles of quorum sensing at each stage of biofilm development, regardless of the type of marine surfaces on which they grow: crucial in the establishment, maturation and dispersion of marine biofilms. Additionally, similar biofilmdependent phenotypes are positively or negatively regulated by quorum sensing in diverse strains, reflecting diverse types of life strategies and adaptations of bacterial cells.

\section{d. Virulence}

Virulence factors are extracellular products released by bacterial cells and are involved in pathogenesis (Liuxy et al., 1996, Austin and Zhang, 2006). Their production represents an important metabolic cost for the cell and thus is strictly regulated (Yang and Defoirdt, 2015). The relationships among virulence and expression of quorum sensing compounds are complex: it has been shown that virulence factors can be either positively or negatively controlled by quorum sensing, either at low cell density or high cell densities. Such complex regulation is interpreted as a need to differently tune the production factors at the different stages of infection (Natrah et al., 2011b). For example, in $V$. harveyi, both the low cell density master regulator AphA and the high cell density master regulator LuxR-type control the production of the type III secretion system 1 (T3SS1). Such tuning of T3SS1 allows a well controlled peak of expression in between the low cell density state and the high cell density state (van Kessel et al., 2013).

At high cell densities, a positive regulation of caseinase, gelatinase, and other types of proteases has been reported in $V$. harveyi (Mok et al., 2003, Natrah et al., 2011b), Vibrio alginolyticus (Rui et al., 2008, Rui et al., 2009), and V. vulnificus (Shao and Hor, 2001). Similarly, the production of metalloproteases (Mok et al., 2003) and extracellular toxins (Manefield et al., 2000) appears positively regulated by quorum sensing, as well as flagellar motility, which is frequently considered an important virulence factor (Yang and Defoirdt, 2015). By contrast, downregulation of chitinase A (Defoirdt et al., 2010), siderophore production (Lilley and Bassler, 2000) by quorum sensing has been evidenced in $V$. harveyi. Lipases and hemolysin are virulence factors whose production appears independent of quorum sensing expression (Natrah et al., 2011b).

\section{e. Emission of colonization factors}

In marine bacteria, quorum sensing regulates many colonization factors in $V$. fischeri colonizing Hawaiian bobtail squid E. scolopes. The production of quorum sensing mutants, combined with the examination of microarray data collected from both mutant and wild-type cultures, provided interesting data. Thus, it has been demonstrated that ain gene expression favors the initiation of squid colonization and, among others, positively regulates cell motility and exopolysaccharide production. At this step of colonization, lux genes are not fully expressed. By contrast, lux gene expression is involved in the production of late colonization factors and in the persistence of strains in the crypts of the squid's light organ. Collectively, these data suggest that the ain-dependent quorum sensing system operates at moderate cell densities, while the luxdependent system activity peaks at very high cells densities, such as those observed in the crypts of the light organ.

\section{f. Horizontal gene transfer}

The existence of quorum sensing-dependent horizontal gene transfer has been demonstrated in $V$. cholerae cultured in biofilm composed of mixed Vibrio species. These processes are under the control of the gene comEA, whose transcription was found to be induced in the presence of AI-1 and AI-2. As the experimental set-up was based on mixed biofilms, it is probable that such horizontal transfer in $V$. cholerae occurs through AIs emitted by other Vibrio species (Antonova and Hammer, 2011). It has also been shown in V. cholerae that the type IV secretion 
system, which permits cell lysis and extracellular DNA acquisition, is also positively regulated by quorum sensing (Papenfort and Bassler, 2016).

The importance of quorum sensing in gene transfer has also been demonstrated in Rhodobacter capsulatus, a model bacterium in microbiology whose close relatives have been detected in marine environments (Zehr et al., 1995, Oz et al., 2005). Interestingly, when the AIs synthase gene gtaI was muted with a $\mathrm{Sp}^{\mathrm{r}}$ cassette, researchers observed a reduction in gene transfer agent production, which was restored by the addition of C16-HSL (Schaefer et al., 2002).

\section{g. Nutrient acquisition}

One of the earliest hypotheses to explain the role of quorum sensing in bacterial cells is that cooperation may favor the acquisition of nutrients (Rosenberg et al. 1977). In this sense, the extracellular hydrolytic enzymes emitted by diverse bacteria are public goods that will benefit the whole community. This hypothesis is not specifically adapted to the marine environment, with a population-level benefit from the secretion of proteases shown in P. aeruginosa cultures (Darch et al., 2012).

In the marine environment, this hypothesis has been explored mostly with bacteria colonizing the phycosphere of microalgae or marine snow. In a paper published in 2012, it has been shown that the epibionts of Trichodesmium rely on quorum sensing to up-regulate their phosphate acquisition by the production of alkaline phosphatases. It appeared that AHLs are involved in this process, while AI-2 production led to a decrease in phosphate uptake (Van Mooy et al., 2012). In a similar vein, $R$. pomeroyi overproduces 3-oxo-C14-HSL when cultured in the presence of dimethylsulfoniopropionate (DMSP) as an energy source. Interestingly, this observation combined with the record of a drastic modification of the cell metabolome suggests that Ruegeria switches to a cooperative lifestyle when cultured with algal DMSP provided as a source of sulfur (Johnson et al., 2016).

Another series of papers revealed interesting links between the production of chemical compounds by decaying algae and the expression of quorum sensing. Indeed, it has been shown that $p$-coumaric acid, a product of algal lignin degradation released by decaying phytoplankton cells, is also the precursor of $p$-coumaroyl-HSL involved in Rhodopseudomonas palustris quorum sensing, as well as in the marine S. pomeroyi DSS-3 strain (Schaefer et al., 2008). In this sense, the production of semiochemicals associated with the release of phytoplanktonic compounds might convey some information about nutrients and exogenously supplied substrates availability within the phycosphere (Schaefer et al., 2008, Buchan et al., 2014). Interestingly, the algae symbiont $D$. shibae controls flagellar biosynthesis with quorum sensing (Patzelt et al., 2013), which potentially enables chemotaxis to microalgae and thus favors the acquisition of nutrients.

The coordination of marine bacteria for nutrient acquisition probably has broader consequences at a global scale, although this hypothesis remains poorly explored. Nonetheless, the reports of Hmelo et al (2011) and Jatt et al. (2015) support similar conclusions. Hmelo et al. (2011) collected and incubated marine sinking particles sampled near Vancouver Island, noticing an increase in hydrolytic enzyme activity when adding commercially available AHLs (Hmelo et al., 2011). Similarly, Jatt et al. (2015) observed an enhancement of alkaline phosphatase activity when adding C10-AHL to a P. ananatis culture initially isolated from marine snow (Jatt et al., 2015). Collectively, these data suggest that quorum sensing may regulate marine snow mineralization kinetics, yet many more observations are required to better characterize and conceptualize the biogeochemical implications of quorum sensing expression in seawater (Moran et al., 2016).

\section{h. Production of antimicrobial compounds}

Quorum sensing is involved in the regulation of many compounds that act on cell density and on community dynamics, such as antimicrobial molecules (Bainton et al., 1992, Wood and Pierson, 
1996). In the marine environment, such observations have been made on many strains producing algacidal compounds. Among those, TDA is an antimicrobial compound that also induces its own synthesis and thus also acts as an AI (Bruhn et al., 2005, Geng et al., 2008, Porsby et al., 2008, Berger et al., 2011). Interestingly, the production of TDA is also dependent on AHLs in diverse Roseobacter species (Rao et al., 2007, Berger et al., 2011, Thole et al., 2012). This production of TDA regulates interesting community traits in the association between Phaeobacter gallaeciensis BS107 and the microalgae Emiliana huxleyi. The bacteria provides growth inducers to the alga, such as auxins during bloom conditions, and produce antibiotics including TDA probably to target algal pathogens (Geng et al., 2008, Thiel et al., 2010). In this symbiotic relationship, P. gallaeciensis receives DMSP produced by the microalgae as a sulfur source (González et al., 1999, Newton et al., 2010).

Different types of algaecides whose production could be under the control of quorum sensing compounds have been identified from marine bacteria (Skerratt et al., 2002, Nakashima et al., 2006, Paul and Pohnert, 2011). For example, Kordia algicida displays algaecide activity due to the emission of proteases, and some experimental data suggest that this expression is quorum sensing regulated (Paul and Pohnert, 2011). Additionally, Skerrat et al. suggested a potential role of AI-2 in the algaecide activity against the dinoflagellate G. catenatum (Skerratt et al., 2002). More recently, it has been shown that the strain Ponticoccus sp. PD-2 isolated from the phycosphere of the microalga Prorocentrum donghaiense regulates its algicidal activity using quorum sensing. This strain produces 3-oxo-C8-HSL and 3-oxo-C10-HSL using two quorum sensing networks (zlaI/R and $z l b I / R)$. The inhibition of quorum sensing activity using $\beta$-cyclodextrin reduced the algicical activity of more than $50 \%$ (Chi et al., 2017).

\section{i. Induction and maintenance of phenotypic heterogeneity within a cell population}

Interestingly, a few reports have suggested that quorum sensing could be involved in the maintenance of population heterogeneity, which is hypothesized to be a survival strategy under fluctuating environmental conditions. It has been suggested that such phenotypic heterogeneity might increase the fitness of the whole population by enhancing survival in a sub-population when facing changing conditions (Grote et al., 2015). Such observations were made initially on $V$. harveyi (now reclassified as Vibrio campbellii). The authors of this study revealed that in a bioluminescent population of cells, only $69 \%$ were effectively emitting light, and that the strength of the bioluminescence was different between cells (Anetzberger et al., 2009). The key LuxO protein in the quorum sensing signaling pathway (see earlier in this chapter for more details) seems to also play a role in these mechanisms, as the culture of a luxO mutant is composed of only glowing cells (Anetzberger et al., 2009).

Interesting data linking quorum sensing and phenotypic heterogeneity were also collected, coupling genetic and transcriptomic studies conducted on the marine D. shibae (Patzelt et al., 2013). In these experiments, the authors revealed that the lack of AHL production in a luxI mutant strain modified the transcription of 344 genes involved in the regulation of many different physiological activities, including cell division, flagellar biosynthesis and sigma factor synthesis. Interestingly, this luxI mutant culture presented a single ovoid phenotype of Dinoroseobacter cells. By contrast, the wild-type phenotype, as well as the mutant culture amended with addition of C18-AHL at saturating concentrations, included more cell morphologies with ovoid, rod-shaped and very elongated cells. In marine bacterial populations, the existence of such a morphological heterogeneity might be an ecological advantage. During phytoplankton blooms, grazing is intense and has been demonstrated to be cell shape dependent. Thus, a bacterial population might enhance its fitness by allowing a proportion of the population to stochastically vary its phenotype and ensuring the survival of at least a fraction of the population during environmental fluctuations (Acar et al., 2008), such as over 
a seasonal marine plankton bloom. Such observations are not specific to the marine environment and remain a subject of interrogation in diverse fields of microbiology (Grote et al., 2015).

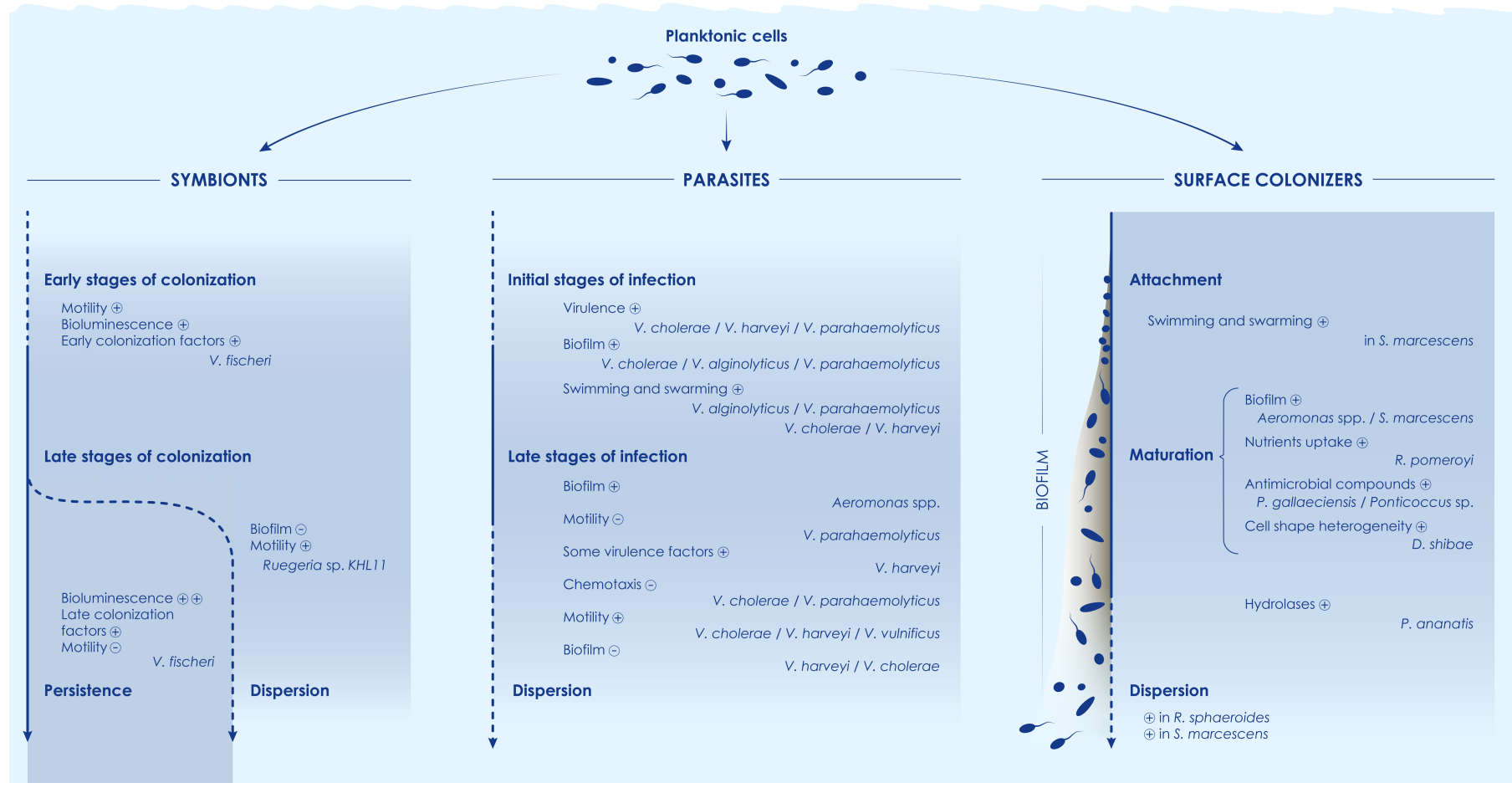

Figure 7 legend: A synthetic picture that attempts to synthesize and order the diversity of quorum sensing-regulated functions in marine environments and biofilms. V. = Vibrio; S. = Serratia; R. pomeroyi $=$ Ruegeria pomeroyi R. sphaeroides $=$ Rhodobacter sphaeroides .

\section{Sourcing and applying quorum sensing inhibitors in the marine environment: aquaculture protection and innovation in green antifouling}

\section{a. A model story: the discovery of antifouling compounds in the red marine alga Delisea pulchra}

The first quorum sensing-inhibiting compound was discovered in seawater. This pioneering research is frequently cited as a model process to identify anti-quorum sensing compounds with potential economic applications. This research story begins with a naturalist observation of $D$. pulchra, a small red benthic macroalgae whose fronds measure a few centimeters. First, these fronds have the particularity of being poorly colonized by different types of organisms. Unlike most other types of marine plants and algae, bacterial abundances on fronds surfaces are significantly lower than those on other seaweed surfaces (Maximilien et al., 1998). Then, it is important to notice that on the east coast of Australia, these algae are subjected to seasonal bleachings (Campbell et al., 2011) that appear in summer when temperature rises. Interestingly, D. pulchra is able to produce halogenated furanones, whose concentrations are reduced during these episodes of bleaching (Campbell et al., 2011).

Interestingly, it has been observed that halogenated furanones share structural similarities with AHLs and it has been hypothesized that they could interfere with quorum sensing signaling pathways (Givskov et al., 1996). These halogenated furanones are able to modify many different bacterial properties, such as swarming in Serratia liquefaciens (Givskov et al., 1996) and Proteus 
mirabilis (Gram et al., 1996), exoenzyme production in diverse bacteria (Kjelleberg et al., 1997) as well as bioluminescence and pigment production (Givskov et al., 1996, Kjelleberg et al., 1997). The molecular and genetic mechanisms underlying the furanones' mode of action were then investigated, and it was demonstrated that these compounds bind to the LuxR receptors and increased their degradation rates turnover (Manefield et al., 2000, Manefield et al., 2002).

Then the relationships between Delisea's bleaching events, temperature increase and bacterial quorum sensing were also investigated. The incubation of $D$. pulchra sporelings in water containing natural bacterioplankton increased their susceptibility to be subjected to bleaching compared to algae immerged in sterile seawater, leading the authors to involve some role for bacteria in bleachings events. Also, the absence of halogenated furanones increased the susceptibility of D. pulcha to bleachings (Campbell et al., 2011) revealing the importance of quorum quenching to limit the effects of this disease. One of the responsible bacteria has been isolated and identified as a Nautella sp., which penetrates algae's tissues (Case et al., 2011). Either the virulence mechanisms remain to be elucidated (Harder et al., 2014), it appears that these bacteria could provoke at least part of the observed summer bleachings and that the production of halogenated furanones allows D. pulchra to control pathogens.

Natural or synthetic halogenated furanones were then tested with some success against common pathogens. It has been shown that these compounds inhibit quorum sensing processes in $P$. aeruginosa biofilms (Hentzer et al., 2002), as well as carbapenem antibiotic synthesis and exoenzyme virulence factor production in Erwinia carotovora, a plant pathogen (Manefield et al., 2001). Quorum sensing inhibiting compounds are usually suspected to avoid any apparition of resistance in targeted bacteria. However this paradigm has to be revisited with recent data and observations. Some $P$. aeruginosa strains were found to be resistant to some of the synthetic halogenated furanones intensively used in laboratories (García-Contreras et al., 2013). The resistance mechanism appears to be linked to the capacity of the strains to increase the efflux of the furanones out of cells (Maeda et al., 2012).

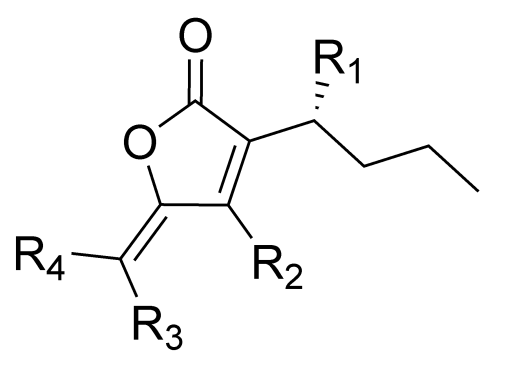

$\begin{array}{lcccc} & \mathrm{R}_{1} & \mathrm{R}_{2} & \mathrm{R}_{3} & \mathrm{R}_{4} \\ \text { Furanone 1 } & \mathrm{H} & \mathrm{Br} & \mathrm{Br} & \mathrm{Br} \\ \text { Furanone 2 } & \mathrm{H} & \mathrm{Br} & \mathrm{H} & \mathrm{Br} \\ \text { Furanone 3 } & \mathrm{OAc} & \mathrm{Br} & \mathrm{H} & \mathrm{Br} \\ \text { Furanone 4 } & \mathrm{OH} & \mathrm{Br} & \mathrm{H} & \mathrm{Br} \\ \text { Furanone 5 } & \mathrm{OAc} & \mathrm{Br} & \mathrm{H} & \mathrm{I} \\ \text { Furanone 6 } & \mathrm{H} & \mathrm{H} & \mathrm{Br} & \mathrm{Br}\end{array}$

Figure 8 legend: Some of the halogenated furanones produced by Delisea pulchra. Redrawn from Manefield et al. 1999. Compound (8) is synthetic.

\section{b. Diversity of quorum quenching compounds isolated from marine organisms}

A large panel of quorum quenching compounds has been isolated from a wide range of marine organisms. These include bacteria, cyanobacteria, fungi, marine sponges, marine algae, cnidarians and Bryozoa. A recent review published by Saurav et al. fully details the current catalog of quorum sensing-inhibiting compounds isolated from seawater (Saurav et al., 2017) and reports 
the existence of 70 marine-derived molecules presenting such activity. This review reveals the wide spectrum of marine organisms and chemical compounds capable of such biological activity. In bacteria, compounds as diverse as phenethylamides, cyclic dipeptides, tyrosol and tyrosol acetate have been found to present quorum quenching activity (Teasdale et al., 2009, Teasdale et al., 2011, Abed et al., 2013, Martínez-Matamoros et al., 2016). In marine fungi, aculenes C, D, E; penicitor; aspergillumarins A, B; meleagrin; and kojic acid were found to be quorum sensing inhibitors (Li et al., 2003, Dobretsov et al., 2011, Kong et al., 2017). In cyanobacteria, malyngamide C, 8-epimalyngamide $\mathrm{C}$, malyngolide and lyngbyic acid showed anti-quorum sensing properties, as well as tumonoic acids; honaucins A, B, C; pitinoic acid; and microcolins A, B (Clark et al., 2008, Kwan et al., 2010, Dobretsov et al., 2011, Kwan et al., 2011, Choi et al., 2012, Montaser et al., 2013). Such biological activity was also reported in manoalides isolated from sponges (Montaser et al., 2013), cembranoids isolated from cnidarians (Tello et al., 2009, Tello et al., 2012) and brominated alkaloids from Bryozoa (Peters et al., 2003).<smiles>O=C1N[C@H](Cc2ccccc2)C(=O)N2CCC[C@H]12</smiles>

cyclo(L-Pro-L-Phe)<smiles>O=c1cc(CO)occ1O</smiles>

Kojic acid

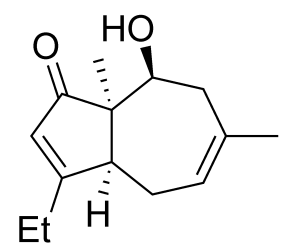

Aculene $\mathrm{E}$<smiles>CCCCCCCC(C/C=C/CCC(=O)O)OC</smiles>

Lyngbyoic acid<smiles>CCCCC(C)/C=C(\C)[C@@H](O)[C@H](C)C(=O)N1CCC[C@H]1C(=O)O</smiles>

Tumonoic acid E<smiles>[R20]C1OC(=O)C=C1[C@H]1CC=C(CC/C=C(\C)CCC2=C(C)CCCC2(C)C)C[C@@H]1O</smiles>

$\mathrm{R}=\mathrm{H}:$ Manoalide

$\mathrm{R}=\mathrm{Ac}:$ Manoalide monoacetate

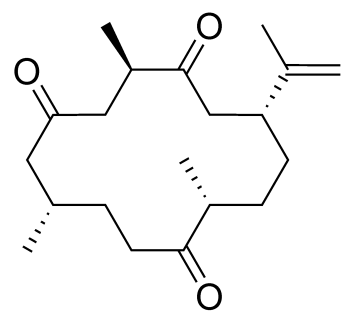

8S-Plexaurolone<smiles>C=CC(C)(C)[C@]12CCCN1[C@H]1Nc3cc(Br)ccc3[C@]12C</smiles>

Dihydroflustramine C

Figure 9 legend: A snapshot of the diversity of quorum sensing-inhibiting compounds.

\section{c. Diversity of marine quorum quenching enzymes}

A large diversity of bacteria are able to produce quorum quenching enzymes, and the use of these enzymes to fight quorum sensing-dependent traits in bacteria is very promising. These enzymes act extracellularly to degrade AIs and can be used in catalytic quantities (Bzdrenga et al., 2017). They are able to disrupt the quorum sensing signal in the nearby environment of bacterial cells and thus do not have to penetrate bacterial cells, facilitating their mode of action and effects. Although various types of enzymes present a such activity (Romero et al., 2015), two major types of quorum quenching enzymes have been described: lactonases (which hydrolyze the lactone ring of AHLs) and acylases (which cleave the amide bond linking the lactone cycles to the acyl side chains in AHLs) (Grandclement et al., 2016). Many studies have tried to use quorum quenching enzymes to 
disrupt the virulence of pathogens or biofilm formation. Specifically, quorum quenching enzymes have been tested against plant pathogens and against biofilm formation on membrane bioreactors and medical devices (Grandclement et al., 2016).

Marine bacteria are an important resource for prospecting new quorum quenching enzymes. In a report published in 2011, Romero et al. screened 166 marine strains and identified 24 that were able to significantly degrade AHLs (Romero et al., 2011a). It has recently been shown that Alteromonas stellipolaris, a bacterium selected among 450 strains isolated from a bivalve hatchery, has a very efficient lactonase activity (Torres et al., 2016). Similarly, enzymatic quorum quenching activities were also detected in corals (Tait et al., 2010, Golberg et al., 2013), and sponges (Saurav et al., 2016a). In the same perspective, metagenomic studies revealed a large diversity of quorum quenching genes in marine microbial communities (Romero et al., 2012, Muras et al., 2018a).

Unsurprisingly, a few research groups attempted to express, characterize and test the potential of quorum quenching enzymes issued from the marine environment. For example, MomL is a lactonase isolated from the Flavobacteria Muricauda olearia Th120, a flounder mucus-derived strain. Interestingly, this enzyme was shown able to significantly reduce the virulence and biofilm formation of P. aeruginosa (Tang et al., 2015). Similarly, a Bacillus licheniformis strain was isolated from dissected guts collected from Indian white shrimps. This enzyme presents a high resistance to acid conditions (likely as a consequence of the native conditions experienced in the gut), has a large spectrum of AHLs that it can degrades, and appears to reduce Vibrio biofilms (Vinoj et al., 2014). Similarly, a wide-spectrum thermostable lactonase has been isolated from the marine bacteria Tenacibaculum sp. 20J (Mayer et al., 2015) which present antbiofilm activity against Streptococcus mutans (Muras et al., 2018b) and against the fish pathogen Edwarsiella tarda (Romero et al., 2014).

\section{d. Applications for biofouling on marine underwater surfaces}

The term "biofouling" refers to the biological colonization by organisms on living and nonliving materials. Such colonization of underwater surfaces by marine organisms causes significant problems, such as biocorrosion, increased frictional forces on boat hulls, obstruction of submerged instruments and devices such as propellers or scientific instruments, and problems in marine aquaculture (Dobretsov et al., 2011, Bloecher et al., 2013). This colonization starts with the development of a bacterial biofilm (microfoulers), which serves as a substrate for the settlement of larger organisms (algae, metazoans : macrofoulers). Thus, fighting biofilm development constitutes a current major challenge in many industries, such as underwater electricity production, boat construction, and naval transportation (Sommerset et al., 2005). Most of the antifouling compounds used are toxic biocides (Dafforn et al., 2011), which deeply impact the natural environment since they are released in the seawater. For example, they accumulate along the food chain, leading to a high concentration of toxic substances in marine mammals. They can also directly affect filterfeeding organisms such as oysters (Champ, 2003, Thomas and Brooks, 2010, Gittens et al., 2013). One possible strategy to overcome these difficulties is to target key mechanisms responsible for biofilm formation without affecting cell viability to select compounds with low toxicity. In this sense, the application of quorum quenching compounds appears to meet these criteria and seems to be a promising strategy against biofouling. Thus, quorum sensing-inhibiting compounds have received growing interest in recent years, especially when considering the interesting results collected on the model macro-algae D. pulchra described above (Rasmussen et al., 2000).

While natural quorum sensing-inhibiting compounds have been widely isolated from a large diversity of living organisms, their effects on marine biofilms remain poorly explored. One reason is that these compounds are produced at low concentrations, which limits their application in the environment (Yang et al., 2016). However, synthetic quorum sensing-inhibiting compounds can now be used. In a pioneering study published in 2011 focusing on natural compounds, Dobretsov et al. screened 78 natural products isolated from marine organisms and terrestrial plants (Dobretsov 
et al., 2011). Among them, $24 \%$ were able to inhibit quorum sensing on the classical reporter strain C. violaceum CV017 without causing toxicity. The authors demonstrated that hymenialdisine, demethoxy encecalin, microcolins A and B and kojic acid (an oxo-pyrone) were involved in these processes, and kojic acid was able to inhibit the formation of biofilms on glass slides. Since then, a few studies have used similar approaches to evaluate the effect of quorum sensing-inhibiting compounds on marine biofilms. In 2016, Yang et al. evaluated the potential antifouling effects of 3 quorum sensing inhibitors (3,4-dibromo-2(5)H-furanone, 4-nitropyridine- $N$-oxide and indole) on the growth of two diatoms that can be found in marine biofilms, Cylindrotheca sp. and Nitzschia closterium. The authors revealed a significant effect on the biofilm formation of these compounds and reported that the production of the polymeric substance was significantly reduced. 4Nitropyridine- $N$-oxide appeared to be the most effective compound (Yang et al., 2016). Additionally, $\mathrm{AI}-2$ based quorum sensing has also been targeted in recent studies to limit biofilm formation. In 2014, Liaqat et al. reported that the penicillic acid is able to inhibit AI-2 production in Halomonas pacifica as well as biofilm formation without affecting bacterial growth and at up to $10 \mu \mathrm{M}$ in concentration (Liaqat et al., 2014).

\section{e. Applications in aquaculture}

Aquaculture is another industry in which quorum quenching-based strategies have potential important applications (Grandclement et al., 2016). The dense breeding conditions along with the growth of this economic sector mean that fish diseases are becoming more prevalent. Prophylactic measures have limited efficacy, while vaccination is effective against some aquatic pathogens but also presents many side effects (Sommerset et al., 2005). The use of antibiotics restrains commercialization of fish culture, as their overuse leads many pathogens to become resistant to these compounds (Akinbowale et al., 2006, Agersø et al., 2007). Thus, there is an important need to renew our panel of methods to fight fish pathogens if sustained growth of the aquaculture economy is to continue. Again, quorum sensing is a key mechanism in the activation of virulence in many fish pathogens; thus, quorum quenching strategies appear to be a very promising research direction in controlling fish diseases (Defoirdt et al., 2011).

One of the first strategies was based on the use of chemical compounds derived from (micro)algae in aquaculture, to protect fishes, shellfishes and crustaceans. It has been shown that natural and synthetic furanones were able to protect the shrimp Artemia franciscana from $V$. harveyi, V. campbellii and V. parahaemolyticus infections (Givskov et al., 1996, Defoirdt et al., 2006). These compounds have also been reported to protect rainbow trout from vibriosis (Rasch et al., 2004). However, these compounds present toxicity for some fishes, such as the rainbow trout. The use of synthetic compounds like brominated thiophenones, which present a much lower toxicity, appears promising (Rasch et al., 2004, Defoirdt et al., 2012). In the same vein, the potential of diverse microalgae to produce quorum quenching compounds has been evaluated, and Chlorella saccharophila has been revealed to present an important potential for use in aquaculture (Natrah et al., 2011a).

Another strategy is the use of quorum quenching enzymes or the provision of probiotics able to deliver such enzymes. The application of these ideas has already achieved some success. For example, carps that were fed quorum quenching AiiA recombinant protein were more resistant to Aeromonas hydrophila (Cao et al., 2012). Additionally, the microbial communities from the guts of the shrimp Penaeus vannamei present AI-1-degrading activity that improved the growth of rotifers in the presence of $V$. harveyi. Similarly, bacterial consortia from the guts of Dicentrarchus labrax and Lates calcarifer were evaluated to protect prawn (Macrobrachium rosenbergii) larviculture (Nhan et al., 2010), and AHL-degrading communities improved the survival of first-feeding turbot larvae (Scophthalmus maximus L.) (Tinh et al., 2008). Such selection of quorum quenching-producing strains also gave interesting preliminary data for biocontrol in coral aquaculture. The strain $A$. 
stellipolaris significantly reduced the pathogenicity of Vibrio mediterranei upon the coral Oculina patagonica (Torres et al., 2016). A few research teams have also tried to deliver to fishes as probiotics Bacillus strains able to produce quorum quenching enzymes. For example, Bacillusrelated strains isolated from the gut of the fish Carassius auratus and emitting quorum quenching enzymes were able to protect zebrafish from infections (Chu et al., 2014). This field of research had led some companies to develop commercial products, such as Biomin (Inzersdorf-Getzersdorf, Austria), which markets the probiotic Aquastar. This product is a Bacillus strain encapsulated with food and producing quorum quenching enzymes to be delivered in shrimp cultures (Grandclement et al., 2016).

\section{Concluding remarks}

Since its discovery in the 70s in the marine environment, quorum sensing has been mostly studied in strains of medical or agronomic interest. The roles and importance of quorum sensing among marine strains remain poorly studied, with the notable exception of Vibrio strains, as many are important pathogens. Thus, a lot of work remains to be done to characterize the diversity of quorum sensing genes, the diversity of quorum sensing compounds and their biological roles in strains of interest in the field of environmental sciences. Additionally, the consequences of quorum sensing expression in biogeochemical cycles have been poorly explored. Another important field of future investigations is the elucidation of quorum sensing roles in the holobionts' microbial balance, as a growing number of studies are revealing the importance of bacteria-eukaryotes (inter)relationships based on quorum sensing compounds emission, perception and inhibition, including in marine models (Pietschke et al., 2017).

Knowledge of quorum sensing can lead to important biotechnological applications, especially in the marine environment, where aquaculture and antifouling industries can benefit from these technologies. While many interesting results have been published, data concerning larger experiments or applications tested in realistic conditions remain scarce. There are diverse possible explanations for such observations: (i) studies are underway in industrial labs and have not been yet published, (ii) negative results were obtained or difficulties were raised when experimenting on larger scales than in research labs, and (iii) the output of these works is protected by industrial secrets and cannot be released to the scientific community. Also, few quorum quenching agents were yet tested for industrial applications, and the catalogue of available natural and synthetic compounds has to be expanded. Whatever the case(s), much more information is required to better evaluate whether quorum quenching strategies can be applied at large scales to solve industrial problems.

\section{BIBLIOGRAPHY}

1. Abed, R.M., Dobretsov, S., Al-Fori, M., Gunasekera, S.P., Sudesh, K., and Paul, V.J. (2013) Quorum-sensing inhibitory compounds from extremophilic microorganisms isolated from a hypersaline cyanobacterial mat. J Ind Microbiol Biotechnol 40, 759-772.

2. Acar, M., Mettetal, J.T., and Van Oudenaarden, A. (2008) Stochastic switching as a survival strategy in fluctuating environments. Nat Genet 40, 471-475.

3. Agers $\varnothing$, Y., Bruun, M.S., Dalsgaard, I., and Larsen, J.L. (2007) The tetracycline resistance gene tet(E) is frequently occurring and present on large horizontally transferable plasmids in Aeromonas spp. from fish farms. Aquaculture 266, 47-52.

4. Akinbowale, O.L., Peng, H., and Barton, M.D. (2006) Antimicrobial resistance in bacteria isolated from aquaculture sources in Australia. J Appl Microbiol 100, 1103-1113.

5. Alagely, A., Krediet, C.J., Ritchie, K.B., and Teplitski, M. (2011) Signaling-mediated cross-talk modulates swarming and biofilm formation in a coral pathogen Serratia marcescens. ISME J $5,1609-1620$. 
6. Allwood, A.C., Walter, M.R., Kamber, B.S., Marshall, C.P., and Burch, I.W. (2006) Stromatolite reef from the early Archaean era of Australia. Nature 441, 714-718.

7. Andersen, J.B., Heydorn, A., Hentzer, M., Eberl, L., Geisenberger, O., Christensen, B.B., Molin, S., and Givskov, M. (2001) gfp-based $N$-acyl homoserine-lactone sensor systems for detection of bacterial communication. Appl Environ Microbiol 67, 575-585.

8. Anetzberger, C., Pirch, T., and Jung, K. (2009) Heterogeneity in quorum sensing-regulated bioluminescence of Vibrio harveyi. Mol Microbiol 73, 267-277.

9. Antonova, E.S. and Hammer, B.K. (2011) Quorum-sensing autoinducer molecules produced by members of a multispecies biofilm promote horizontal gene transfer to Vibrio cholerae. FEMS Microbiol Lett 322, 68-76.

10. Austin, B. and Zhang, X.H. (2006) Vibrio harveyi: a significant pathogen of marine vertebrates and invertebrates. Lett Appl Microbiol 43, 119-124.

11. Ayé, A.M., Bonnin-Jusserand, M., Brian-Jaisson, F., Ortalo-Magné, A., Culioli, G., Nevry, R.K., Rabah, N., Blache, Y., and Molmeret, M. (2015) Modulation of violacein production and phenotypes associated with biofilm by exogenous quorum sensing $N$-acylhomoserine lactones in the marine bacterium Pseudoalteromonas ulvae TC14. Microbiology 161, 20392051.

12. Bachofen, R. and Schenk, A. (1998) Quorum sensing autoinducers: Do they play a role in natural microbial habitats? Microbiol Res 153, 61-63.

13. Bainton, N.J., Stead, P., Chhabra, S.R., Bycroft, B.W., Salmond, G.P., Stewart, G.S., and Williams, P. (1992) $N$-(3-oxohexanoyl)-L-homoserine lactone regulates carbapenem antibiotic production in Erwinia carotovora. Biochem J 288 ( Pt 3), 997-1004.

14. Béjà, O., Suzuki, M.T., Heidelberg, J.F., Nelson, W.C., Preston, C.M., Hamada, T., Eisen, J.A., Fraser, C.M., and DeLong, E.F. (2002) Unsuspected diversity among marine aerobic anoxygenic phototrophs. Nature 415, 630-633.

15. Bell, W. and Mitchell, R. (1972) Chemotactic and growth responses of marine bacteria to algal extracellular products. Biol Bull 143, 265-277.

16. Berger, M., Neumann, A., Schulz, S., Simon, M., and Brinkhoff, T. (2011) Tropodithietic acid production in Phaeobacter gallaeciensis is regulated by $N$-acyl homoserine lactone-mediated quorum sensing. J Bacteriol 193, 6576-6585.

17. Biswa, P. and Doble, M. (2013) Production of acylated homoserine lactone by gram-positive bacteria isolated from marine water. FEMS Microbiol Lett 343, 34-41.

18. Blanchet, E., Prado, S., Stien, D., Oliveira da Silva, J., Ferandin, Y., Batailler, N., Intertaglia, L., Escargueil, A., and Lami, R. (2017) Quorum sensing and quorum quenching in the mediterranean seagrass Posidonia oceanica microbiota. Front Mar Sci 4, 218.

19. Bloecher, N., Olsen, Y., and Guenther, J. (2013) Variability of biofouling communities on fish cage nets: A 1-year field study at a Norwegian salmon farm. Aquaculture 416, 302-309.

20. Bodor, A., Elxnat, B., Thiel, V., Schulz, S., and Wagner-Dobler, I. (2008) Potential for luxS related signalling in marine bacteria and production of autoinducer-2 in the genus Shewanella. BMC Microbiol 8, 13.

21. Bose, U., Ortori, C.A., Sarmad, S., Barrett, D.A., Hewavitharana, A.K., Hodson, M.P., Fuerst, J.A., Shaw, P.N., and Boden, R. (2017) Production of $N$-acyl homoserine lactones by the spongeassociated marine actinobacteria Salinispora arenicola and Salinispora pacifica. FEMS Microbiol Lett 364, fnx002.

22. Brinkhoff, T., Bach, G., Heidorn, T., Liang, L., Schlingloff, A., and Simon, M. (2004) Antibiotic production by a Roseobacter clade-affiliated species from the German Wadden Sea and its antagonistic effects on indigenous isolates. Appl Environ Microbiol 70, 2560-2565.

23. Britstein, M., Devescovi, G., Handley, K.M., Malik, A., Haber, M., Saurav, K., Teta, R., Costantino, V., Burgsdorf, I., and Gilbert, J.A. (2016) A new N-Acyl homoserine lactone synthase in an 
uncultured symbiont of the Red Sea sponge Theonella swinhoei. Applied Environ Microbiol 82, 1274-1285.

24. Britstein, M., Saurav, K., Teta, R., Sala, G.D., Bar-Shalom, R., Stoppelli, N., Zoccarato, L., Costantino, V., and Steindler, L. (2017) Identification and chemical characterization of $\mathrm{N}$ acyl-homoserine lactone quorum sensing signals across sponge species and time. Fems Microbiol Ecol.

25. Bruhn, J.B., Nielsen, K.F., Hjelm, M., Hansen, M., Bresciani, J., Schulz, S., and Gram, L. (2005) Ecology, inhibitory activity, and morphogenesis of a marine antagonistic bacterium belonging to the Roseobacter clade. Appl Environ Microbiol 71, 7263-7270.

26. Buchan, A., LeCleir, G.R., Gulvik, C.A., and Gonzalez, J.M. (2014) Master recyclers: features and functions of bacteria associated with phytoplankton blooms. Nat Rev Microbiol 12, 686-698.

27. Burton, E.O., Read, H.W., Pellitteri, M.C., and Hickey, W.J. (2005) Identification of acylhomoserine lactone signal molecules produced by Nitrosomonas europaea strain Schmidt. Appl Environ Microbiol 71, 4906-4909.

28. Bzdrenga, J., Daude, D., Remy, B., Jacquet, P., Plener, L., Elias, M., and Chabriere, E. (2017) Biotechnological applications of quorum quenching enzymes. Chem Biol Interact 267, 104115.

29. Campbell, A.H., Harder, T., Nielsen, S., Kjelleberg, S., and Steinberg, P.D. (2011) Climate change and disease: bleaching of a chemically defended seaweed. Global Change Biol 17, 2958-2970.

30. Canfield, D.E. (2006) Biochemistry: gas with an ancient history. Nature 440, 426-427.

31. Cao, Y., He, S., Zhou, Z., Zhang, M., Mao, W., Zhang, H., and Yao, B. (2012) Orally administered thermostable $N$-acyl homoserine lactonase from Bacillus sp. strain AI96 attenuates Aeromonas hydrophila infection in zebrafish. Appl Environ Microbiol 78, 1899-1908.

32. Case, R.J., Longford, S.R., Campbell, A.H., Low, A., Tujula, N., Steinberg, P.D., and Kjelleberg, S. (2011) Temperature induced bacterial virulence and bleaching disease in a chemically defended marine macroalga. Environ Microbiol 13, 529-537.

33. Certner, R.H. and Vollmer, S.V. (2015) Evidence for autoinduction and quorum sensing in white band disease-causing microbes on Acropora cervicornis. Sci Rep 5, 11134.

34. Champ, M.A. (2003) Economic and environmental impacts on ports and harbors from the convention to ban harmful marine anti-fouling systems. Mar Pollut Bull 46, 935-940.

35. Charlton, T.S., De Nys, R., Netting, A., Kumar, N., Hentzer, M., Givskov, M., and Kjelleberg, S. (2000) A novel and sensitive method for the quantification of $N-3$ - oxoacyl homoserine lactones using gas chromatography-mass spectrometry: application to a model bacterial biofilm. Environ Microbiol 2, 530-541.

36. Chen, X., Schauder, S., Potier, N., Van Dorsselaer, A., Pelczer, I., Bassler, B.L., and Hughson, F.M. (2002) Structural identification of a bacterial quorum-sensing signal containing boron. Nature 415, 545-549.

37. Chi, W., Zheng, L., He, C., Han, B., Zheng, M., Gao, W., Sun, C., Zhou, G., and Gao, X. (2017) Quorum sensing of microalgae associated marine Ponticoccus sp. PD-2 and its algicidal function regulation. $A M B$ Express 7, 59.

38. Choi, H., Mascuch, S.J., Villa, F.A., Byrum, T., Teasdale, M.E., Smith, J.E., Preskitt, L.B., Rowley, D.C., Gerwick, L., and Gerwick, W.H. (2012) Honaucins A-C, Potent Inhibitors of inflammation and bacterial quorum sensing: synthetic derivatives and structure-activity relationships. Chem Biol 19, 589-598.

39. Chu, W., Zhou, S., Zhu, W., and Zhuang, X. (2014) Quorum quenching bacteria Bacillus sp. QSI1 protect zebrafish (Danio rerio) from Aeromonas hydrophila infection. Sci Rep 4, 5446. 
40. Clark, B.R., Engene, N., Teasdale, M.E., Rowley, D.C., Matainaho, T., Valeriote, F.A., and Gerwick, W.H. (2008) Natural products chemistry and taxonomy of the marine cyanobacterium Blennothrix cantharidosmum.J Nat Prod 71, 1530-1537.

41. Costantino, V., Della Sala, G., Saurav, K., Teta, R., Bar-Shalom, R., Mangoni, A., and Steindler, L. (2017) Plakofuranolactone as a quorum quenching agent from the Indonesian sponge Plakortis cf. lita. Mar Drugs 15, 59.

42. Croxatto, A., Chalker, V.J., Lauritz, J., Jass, J., Hardman, A., Williams, P., Camara, M., and Milton, D.L. (2002) VanT, a homologue of Vibrio harveyi LuxR, regulates serine, metalloprotease, pigment, and biofilm production in Vibrio anguillarum. J Bacteriol 184, 1617-1629.

43. Cude, W.N. and Buchan, A. (2013) Acyl-homoserine lactone-based quorum sensing in the Roseobacter clade: complex cell-to-cell communication controls multiple physiologies. Front Microbiol 4, 336.

44. Dafforn, K.A., Lewis, J.A., and Johnston, E.L. (2011) Antifouling strategies: history and regulation, ecological impacts and mitigation. Mar Pollut Bull 62, 453-465.

45. Darch, S.E., West, S.A., Winzer, K., and Diggle, S.P. (2012) Density-dependent fitness benefits in quorum-sensing bacterial populations. P Natl Acad Sci USA 109, 8259-8263.

46. Davies, D.G., Parsek, M.R., Pearson, J.P., Iglewski, B.H., Costerton, J.W., and Greenberg, E.P. (1998) The involvement of cell-to-cell signals in the development of a bacterial biofilm. Science 280, 295-298.

47. De Keersmaecker, S.C., Sonck, K., and Vanderleyden, J. (2006) Let LuxS speak up in AI-2 signaling. Trends Microbiol 14, 114-119.

48. Decho, A.W., Frey, R.L., and Ferry, J.L. (2011) Chemical challenges to bacterial AHL signaling in the environment. Chem Rev 111, 86-99.

49. Decho, A.W., Visscher, P.T., Ferry, J., Kawaguchi, T., He, L., Przekop, K.M., Norman, R.S., and Reid, R.P. (2009) Autoinducers extracted from microbial mats reveal a surprising diversity of $N$ - acylhomoserine lactones (AHLs) and abundance changes that may relate to diel $\mathrm{pH}$. Environ Microbiol 11, 409-420.

50. Defoirdt, T., Benneche, T., Brackman, G., Coenye, T., Sorgeloos, P., and Scheie, A.A. (2012) A quorum sensing-disrupting brominated thiophenone with a promising therapeutic potential to treat luminescent vibriosis. PLoS One 7, e41788.

51. Defoirdt, T., Crab, R., Wood, T.K., Sorgeloos, P., Verstraete, W., and Bossier, P. (2006) Quorum sensing-disrupting brominated furanones protect the gnotobiotic brine shrimp Artemia franciscana from pathogenic Vibrio harveyi, Vibrio campbellii, and Vibrio parahaemolyticus isolates. Appl Environ Microbiol 72, 6419-6423.

52. Defoirdt, T., Darshanee Ruwandeepika, H.A., Karunasagar, I., Boon, N., and Bossier, P. (2010) Quorum sensing negatively regulates chitinase in Vibrio harveyi. Environ Microbiol Rep 2, 4449.

53. Defoirdt, T., Sorgeloos, P., and Bossier, P. (2011) Alternatives to antibiotics for the control of bacterial disease in aquaculture. Curr Opin Microbiol 14, 251-258.

54. Delalande, L., Faure, D., Raffoux, A., Uroz, S., D'Angelo-Picard, C., Elasri, M., Carlier, A., Berruyer, R., Petit, A., Williams, P., and Dessaux, Y. (2005) $N$-hexanoyl-L-homoserine lactone, a mediator of bacterial quorum-sensing regulation, exhibits plant-dependent stability and may be inactivated by germinating Lotus corniculatus seedlings. Fems Microbiol Ecol 52, 1320.

55. Doberva, M., Sanchez-Ferandin, S., Toulza, E., Lebaron, P., and Lami, R. (2015) Diversity of quorum sensing autoinducer synthases in the Global Ocean Sampling metagenomic database. Aquat Microb Ecol 74, 107-119. 
56. Doberva, M., Stien, D., Sorres, J., Hue, N., Sanchez-Ferandin, S., Eparvier, V., Ferandin, Y., Lebaron, P., and Lami, R. (2017) Large diversity and original structures of acyl-homoserine lactones in strain MOLA 401, a marine Rhodobacteraceae bacterium. Front Microbiol 8, 1152.

57. Dobretsov, S., Teplitski, M., Bayer, M., Gunasekera, S., Proksch, P., and Paul, V.J. (2011) Inhibition of marine biofouling by bacterial quorum sensing inhibitors. Biofouling 27, 893905.

58. Eberhard, A., Burlingame, A.L., Eberhard, C., Kenyon, G.L., Nealson, K.H., and Oppenheimer, N.J. (1981) Structural identification of autoinducer of Photobacterium fischeri luciferase. Biochemistry 20, 2444-2449.

59. Engebrecht, J., Nealson, K., and Silverman, M. (1983) Bacterial bioluminescence: isolation and genetic analysis of functions from Vibrio fischeri. Cell 32, 773-781.

60. Feazel, L.M., Spear, J.R., Berger, A.B., Harris, J.K., Frank, D.N., Ley, R.E., and Pace, N.R. (2008) Eucaryotic diversity in a hypersaline microbial mat. Appl Environ Microbiol 74, 329-332.

61. Fowler, S.W. and Knauer, G.A. (1986) Role of large particles in the transport of elements and organic-compounds through the oceanic water column. Prog Oceanogr 16, 147-194.

62. Fuqua, W.C., Winans, S.C., and Greenberg, E.P. (1994) Quorum sensing in bacteria: the LuxRLuxI family of cell density-responsive transcriptional regulators. J Bacteriol 176, 269-275.

63. Gantner, S., Schmid, M., Durr, C., Schuhegger, R., Steidle, A., Hutzler, P., Langebartels, C., Eberl, L., Hartmann, A., and Dazzo, F.B. (2006) In situ quantitation of the spatial scale of calling distances and population density-independent $N$-acylhomoserine lactone-mediated communication by rhizobacteria colonized on plant roots. Fems Microbiol Ecol 56, 188-194.

64. Garcia-Aljaro, C., Vargas-Cespedes, G.J., and Blanch, A.R. (2012) Detection of acylated homoserine lactones produced by Vibrio spp. and related species isolated from water and aquatic organisms. J Appl Microbiol 112, 383-389.

65. García-Contreras, R., Martínez-Vázquez, M., Velázquez Guadarrama, N., Villegas Pañeda, A.G., Hashimoto, T., Maeda, T., Quezada, H., and Wood, T.K. (2013) Resistance to the quorumquenching compounds brominated furanone C-30 and 5-fluorouracil in Pseudomonas aeruginosa clinical isolates. Pathog Dis 68, 8-11.

66. Gardères, J., Henry, J., Bernay, B., Ritter, A., Zatylny-Gaudin, C., Wiens, M., Müller, W.E.G., and Le Pennec, G. (2014) Cellular effects of bacterial $N$-3-oxo-dodecanoyl-L-homoserine lactone on the sponge Suberites domuncula (Olivi, 1792): Insights into an intimate inter-kingdom dialogue. PloS one 9, e97662.

67. Gardères, J., Taupin, L., Saïdin, J.B., Dufour, A., and Le Pennec, G. (2012) N-acyl homoserine lactone production by bacteria within the sponge Suberites domuncula (Olivi, 1792) (Porifera, Demospongiae). Mar Biol 159, 1685-1692.

68. Geng, H. and Belas, R. (2010) Molecular mechanisms underlying Roseobacter-phytoplankton symbioses. Curr Opin Biotechnol 21, 332-338.

69. Geng, H., Bruhn, J.B., Nielsen, K.F., Gram, L., and Belas, R. (2008) Genetic dissection of tropodithietic acid biosynthesis by marine Roseobacters. Appl Environ Microbiol 74, 15351545.

70. Gilson, L., Kuo, A., and Dunlap, P.V. (1995) AinS and a new family of autoinducer synthesis proteins. J Bacteriol 177, 6946-6951.

71. Girard, L., Blanchet, E., Intertaglia, L., Baudart, J., Stien, D., Suzuki, M., Lebaron, P., and Lami, R. (2017) Characterization of $N$-acyl homoserine lactones in Vibrio tasmaniensis LGP32 by a biosensor-based UHPLC-HRMS/MS method. Sensors 17, 906.

72. Gittens, J.E., Smith, T.J., Suleiman, R., and Akid, R. (2013) Current and emerging environmentally-friendly systems for fouling control in the marine environment. Biotechnol Adv 31, 1738-1753. 
73. Givskov, M., de Nys, R., Manefield, M., Gram, L., Maximilien, R., Eberl, L., Molin, S., Steinberg, P.D., and Kjelleberg, S. (1996) Eukaryotic interference with homoserine lactone-mediated prokaryotic signalling. J Bacteriol 178, 6618-6622.

74. Golberg, K., Eltzov, E., Shnit-Orland, M., Marks, R.S., and Kushmaro, A. (2011) Characterization of quorum sensing signals in coral-associated bacteria. Microb Ecol 61, 783792.

75. Golberg, K., Pavlov, V., Marks, R.S., and Kushmaro, A. (2013) Coral-associated bacteria, quorum sensing disrupters, and the regulation of biofouling. Biofouling 29, 669-682.

76. González, J.M., Kiene, R.P., and Moran, M.A. (1999) Transformation of sulfur compounds by an abundant lineage of marine bacteria in the $\alpha$-subclass of the class Proteobacteria. Appl Environ Microbiol 65, 3810-3819.

77. Graf, J. and Ruby, E.G. (1998) Host-derived amino acids support the proliferation of symbiotic bacteria. Proc Natl Acad Sci U S A 95, 1818-1822.

78. Gram, L., de Nys, R., Maximilien, R., Givskov, M., Steinberg, P., and Kjelleberg, S. (1996) Inhibitory effects of secondary metabolites from the Red Alga Delisea pulchra on swarming motility of Proteus mirabilis. Appl Environ Microbiol 62, 4284-4287.

79. Gram, L., Grossart, H.P., Schlingloff, A., and Kiorboe, T. (2002) Possible quorum sensing in marine snow bacteria: production of acylated homoserine lactones by Roseobacter strains isolated from marine snow. Appl Environ Microbiol 68, 4111-4116.

80. Grandclement, C., Tannieres, M., Morera, S., Dessaux, Y., and Faure, D. (2016) Quorum quenching: role in nature and applied developments. FEMS Microbiol Rev 40, 86-116.

81. Greenberg, E., Hastings, J., and Ulitzur, S. (1979) Induction of luciferase synthesis in Beneckea harveyi by other marine bacteria. Arch Microbiol 120, 87-91.

82. Grote, J., Krysciak, D., and Streit, W.R. (2015) Phenotypic heterogeneity, a phenomenon that may explain why quorum sensing does not always result in truly homogenous cell behavior. Appl Environ Microbiol 81, 5280-5289.

83. Gu, D., Liu, H., Yang, Z., Zhang, Y., and Wang, Q. (2016) Chromatin immunoprecipitation sequencing technology reveals global regulatory roles of low-cell-density quorum-sensing regulator AphA in the pathogen Vibrio alginolyticus. J Bacteriol 198, 2985-2999.

84. Hadfield, M.G. (2011) Biofilms and marine invertebrate larvae: what bacteria produce that larvae use to choose settlement sites. Annu Rev Mar Sci 3, 453-470.

85. Hadfield, M.G. and Paul, V.J. (2001) Natural chemical cues for settlement and metamorphosis of marine invertebrate larvae. Marine chemical ecology, 431-461.

86. Harder, T., Rice, S.A., Dobretsov, S., Thomas, T., Carre-Mlouka, A., Kjelleberg, S., Steinberg, P.D., and McDougald, D. (2014) Bacterial Communication Systems. Outstanding Marine Molecules: Chemistry, Biology, Analysis, 173-187.

87. Henke, J.M. and Bassler, B.L. (2004) Three parallel quorum-sensing systems regulate gene expression in Vibrio harveyi. J Bacteriol 186, 6902-6914.

88. Hentschel, U., Fieseler, L., Wehrl, M., Gernert, C., Steinert, M., Hacker, J., and Horn, M. (2003) Microbial diversity of marine sponges. In Sponges (Porifera), pp. 59-88, Springer.

89. Hentzer, M., Riedel, K., Rasmussen, T.B., Heydorn, A., Andersen, J.B., Parsek, M.R., Rice, S.A., Eberl, L., Molin, S., Hoiby, N., Kjelleberg, S., and Givskov, M. (2002) Inhibition of quorum sensing in Pseudomonas aeruginosa biofilm bacteria by a halogenated furanone compound. Microbiology 148, 87-102.

90. Higgins, D.A., Pomianek, M.E., Kraml, C.M., Taylor, R.K., Semmelhack, M.F., and Bassler, B.L. (2007) The major Vibrio cholerae autoinducer and its role in virulence factor production. Nature 450, 883-886.

91. Hmelo, L. and Van Mooy, B.A.S. (2009) Kinetic constraints on acylated homoserine lactonebased quorum sensing in marine environments. Aquat Microb Ecol 54, 127-133. 
92. Hmelo, L.R., Mincer, T.J., and Van Mooy, B.A. (2011) Possible influence of bacterial quorum sensing on the hydrolysis of sinking particulate organic carbon in marine environments. Environ Microbiol Rep 3, 682-688.

93. Huang, Y.-L., Ki, J.-S., Case, R.J., and Qian, P.-Y. (2008) Diversity and acyl-homoserine lactone production among subtidal biofilm-forming bacteria. Aquat Microb Ecol 52, 185-193.

94. Huang, Y.L., Ki, J.S., Lee, O.O., and Qian, P.Y. (2009) Evidence for the dynamics of Acyl homoserine lactone and AHL-producing bacteria during subtidal biofilm formation. ISME J 3 , 296-304.

95. Hunter, G.A. and Keener, J.P. (2014) Mechanisms underlying the additive and redundant Qrr phenotypes in Vibrio harveyi and Vibrio cholerae.J Theor Biol 340, 38-49.

96. Jatt, A.N., Tang, K., Liu, J., Zhang, Z., and Zhang, X.H. (2015) Quorum sensing in marine snow and its possible influence on production of extracellular hydrolytic enzymes in marine snow bacterium Pantoea ananatis B9. Fems Microbiol Ecol 91, 1-13.

97. Ji, G., Beavis, R.C., and Novick, R.P. (1995) Cell density control of staphylococcal virulence mediated by an octapeptide pheromone. Proc Natl Acad Sci U S A 92, 12055-12059.

98. Johnson, W.M., Kido Soule, M.C., and Kujawinski, E.B. (2016) Evidence for quorum sensing and differential metabolite production by a marine bacterium in response to DMSP. ISME J $10,2304-2316$.

99. Joint, I., Tait, K., Callow, M.E., Callow, J.A., Milton, D., Williams, P., and Camara, M. (2002) Cellto-cell communication across the prokaryote-eukaryote boundary. Science 298, 1207.

100. Kaufmann, G.F., Sartorio, R., Lee, S.H., Rogers, C.J., Meijler, M.M., Moss, J.A., Clapham, B., Brogan, A.P., Dickerson, T.J., and Janda, K.D. (2005) Revisiting quorum sensing: Discovery of additional chemical and biological functions for 3-oxo- $N$-acylhomoserine lactones. Proc Natl Acad Sci U S A 102, 309-314.

101. Kelly, R.C., Bolitho, M.E., Higgins, D.A., Lu, W., Ng, W.L., Jeffrey, P.D., Rabinowitz, J.D., Semmelhack, M.F., Hughson, F.M., and Bassler, B.L. (2009) The Vibrio cholerae quorumsensing autoinducer CAI-1: analysis of the biosynthetic enzyme CqsA. Nat Chem Biol 5, 891895.

102. Kimes, N.E., Grim, C.J., Johnson, W.R., Hasan, N.A., Tall, B.D., Kothary, M.H., Kiss, H., Munk, A.C., Tapia, R., Green, L., Detter, C., Bruce, D.C., Brettin, T.S., Colwell, R.R., and Morris, P.J. (2012) Temperature regulation of virulence factors in the pathogen Vibrio coralliilyticus. ISME J 6 , 835-846.

103. Kiørboe, T. (2001) Formation and fate of marine snow: small-scale processes with largescale implications. Sci Mar 65, 57-71.

104. Kjelleberg, S., Steinberg, P., Givskov, M., Gram, L., Manefield, M., and De Nys, R. (1997) Do marine natural products interfere with prokaryotic AHL regulatory systems? Aquat Microb Ecol 13, 85-93.

105. Kong, F.D., Zhou, L.M., Ma, Q.Y., Huang, S.Z., Wang, P., Dai, H.F., and Zhao, Y.X. (2017) Metabolites with Gram-negative bacteria quorum sensing inhibitory activity from the marine animal endogenic fungus Penicillium sp. SCS-KFD08. Arch Pharm Res 40, 25-31.

106. Krick, A., Kehraus, S., Eberl, L., Riedel, K., Anke, H., Kaesler, I., Graeber, I., Szewzyk, U., and Konig, G.M. (2007) A marine Mesorhizobium sp. produces structurally novel long-chain $N$ acyl-L-homoserine lactones. Appl Environ Microbiol 73, 3587-3594.

107. Kwan, J.C., Meickle, T., Ladwa, D., Teplitski, M., Paul, V., and Luesch, H. (2011) Lyngbyoic acid, a "tagged" fatty acid from a marine cyanobacterium, disrupts quorum sensing in Pseudomonas aeruginosa. Mol Biosyst 7, 1205-1216.

108. Kwan, J.C., Teplitski, M., Gunasekera, S.P., Paul, V.J., and Luesch, H. (2010) Isolation and biological evaluation of 8-epi-malyngamide $\mathrm{C}$ from the Floridian marine cyanobacterium Lyngbya majuscula. J Nat Prod 73, 463-466. 
109. Labbate, M., Zhu, H., Thung, L., Bandara, R., Larsen, M.R., Willcox, M.D.P., Givskov, M., Rice, S.A., and Kjelleberg, S. (2007) Quorum-sensing regulation of adhesion in Serratia marcescens MG1 is surface dependent. J Bacteriol 189, 2702-2711.

110. Landa, M., Burns, A.S., Roth, S.J., and Moran, M.A. (2017) Bacterial transcriptome remodeling during sequential co-culture with a marine dinoflagellate and diatom. ISME J 11, 2677-2690.

111. Laue, B.E., Jiang, Y., Chhabra, S.R., Jacob, S., Stewart, G.S., Hardman, A., Downie, J.A., O'Gara, F., and Williams, P. (2000) The biocontrol strain Pseudomonas fluorescens F113 produces the Rhizobium small bacteriocin, $N$-(3-hydroxy-7-cis-tetradecenoyl)homoserine lactone, via HdtS, a putative novel $N$-acylhomoserine lactone synthase. Microbiology 146 ( Pt 10), 2469 2480.

112. Lee, J.H., Rhee, J.E., Park, U., Ju, H.M., Lee, B.C., Kim, T.S., Jeong, H.S., and Choi, S.H. (2007) Identification and functional analysis of Vibrio vulnificus SmcR, a novel global regulator.J Microbiol Biotechnol 17, 325-334.

113. Lenz, D.H., Mok, K.C., Lilley, B.N., Kulkarni, R.V., Wingreen, N.S., and Bassler, B.L. (2004) The small RNA chaperone Hfq and multiple small RNAs control quorum sensing in Vibrio harveyi and Vibrio cholerae. Cell 118, 69-82.

114. Ley, R.E., Harris, J.K., Wilcox, J., Spear, J.R., Miller, S.R., Bebout, B.M., Maresca, J.A., Bryant, D.A., Sogin, M.L., and Pace, N.R. (2006) Unexpected diversity and complexity of the Guerrero Negro hypersaline microbial mat. Appl Environ Microbiol 72, 3685-3695.

115. Li, X., Jeong, J.H., Lee, K.T., Rho, J.R., Choi, H.D., Kang, J.S., and Son, B.W. (2003) $\gamma$-Pyrone derivatives, kojic acid methyl ethers from a marine-derived fungus Altenaria sp. Arch Pharm Res 26, 532-534.

116. Liaqat, I., Bachmann, R.T., and Edyvean, R.G. (2014) Type 2 quorum sensing monitoring, inhibition and biofilm formation in marine microrganisms. Curr Microbiol 68, 342-351.

117. Lilley, B.N. and Bassler, B.L. (2000) Regulation of quorum sensing in Vibrio harveyi by LuxO and sigma-54. Mol Microbiol 36, 940-954.

118. Liuxy, P.C., Lee, K.K., and Chen, S.N. (1996) Pathogenicity of different isolates of Vibrio harveyi in tiger prawn, Penaeus monodon. Lett Appl Microbiol 22, 413-416.

119. Lupp, C. and Ruby, E.G. (2005) Vibrio fischeri uses two quorum-sensing systems for the regulation of early and late colonization factors. J Bacteriol 187, 3620-3629.

120. Lupp, C., Urbanowski, M., Greenberg, E.P., and Ruby, E.G. (2003) The Vibrio fischeri quorum - sensing systems ain and lux sequentially induce luminescence gene expression and are important for persistence in the squid host. Mol Microbiol 50, 319-331.

121. Lynch, M.J., Swift, S., Kirke, D.F., Keevil, C.W., Dodd, C.E., and Williams, P. (2002) The regulation of biofilm development by quorum sensing in Aeromonas hydrophila. Environ Microbiol 4, 18-28.

122. Maeda, T., Garcia-Contreras, R., Pu, M., Sheng, L., Garcia, L.R., Tomas, M., and Wood, T.K. (2012) Quorum quenching quandary: resistance to antivirulence compounds. ISME J 6, 493501.

123. Manefield, M., Harris, L., Rice, S.A., de Nys, R., and Kjelleberg, S. (2000) Inhibition of luminescence and virulence in the black tiger prawn (Penaeus monodon) pathogen Vibrio harveyi by intercellular signal antagonists. Appl Environ Microbiol 66, 2079-2084.

124. Manefield, M., Rasmussen, T.B., Henzter, M., Andersen, J.B., Steinberg, P., Kjelleberg, S., and Givskov, M. (2002) Halogenated furanones inhibit quorum sensing through accelerated LuxR turnover. Microbiology 148, 1119-1127.

125. Manefield, M., Welch, M., Givskov, M., Salmond, G.P., and Kjelleberg, S. (2001) Halogenated furanones from the red alga, Delisea pulchra, inhibit carbapenem antibiotic synthesis and exoenzyme virulence factor production in the phytopathogen Erwinia carotovora. FEMS Microbiol Lett 205, 131-138. 
126. Martínez-Matamoros, D., Laiton Fonseca, M., Duque, C., Ramos, F.A., and Castellanos, L. (2016) Screening of marine bacterial strains as source of quorum sensing inhibitors (QSI): First chemical study of Oceanobacillus profundus (RKHC-62B). Vitae 23, 30-47.

127. Maximilien, R., de Nys, R., Holmstrom, C., Gram, L., Givskov, M., Crass, K., Kjelleberg, S., and Steinberg, P.D. (1998) Chemical mediation of bacterial surface colonisation by secondary metabolites from the red alga Delisea pulchra. Aquat Microb Ecol 15, 233-246.

128. Mayer, C., Romero, M., Muras, A., and Otero, A. (2015) Aii20J, a wide-spectrum thermostable $\mathrm{N}$-acylhomoserine lactonase from the marine bacterium Tenacibaculum sp 20J, can quench AHL-mediated acid resistance in Escherichia coli. Appl Microbiol Biot 99, 9523-9539.

129. McClean, K.H., Winson, M.K., Fish, L., Taylor, A., Chhabra, S.R., Camara, M., Daykin, M., Lamb, J.H., Swift, S., Bycroft, B.W., Stewart, G.S., and Williams, P. (1997) Quorum sensing and Chromobacterium violaceum: exploitation of violacein production and inhibition for the detection of $N$-acylhomoserine lactones. Microbiology 143 ( Pt 12), 3703-3711.

130. McLean, R.J., Whiteley, M., Stickler, D.J., and Fuqua, W.C. (1997) Evidence of autoinducer activity in naturally occurring biofilms. FEMS Microbiol Lett 154, 259-263.

131. Meyer, J.L., Gunasekera, S.P., Scott, R.M., Paul, V.J., and Teplitski, M. (2016) Microbiome shifts and the inhibition of quorum sensing by black band disease cyanobacteria. ISME J 10, 12041216.

132. Miller, S.D., Haddock, S.H., Elvidge, C.D., and Lee, T.F. (2005) Detection of a bioluminescent milky sea from space. Proc Natl Acad Sci U S A 102, 14181-14184.

133. Miller, S.T., Xavier, K.B., Campagna, S.R., Taga, M.E., Semmelhack, M.F., Bassler, B.L., and Hughson, F.M. (2004) Salmonella typhimurium recognizes a chemically distinct form of the bacterial quorum-sensing signal AI-2. Mol Cell 15, 677-687.

134. Milton, D.L. (2006) Quorum sensing in vibrios: complexity for diversification. Int J Med Microbiol 296, 61-71.

135. Mohamed, N.M., Cicirelli, E.M., Kan, J., Chen, F., Fuqua, C., and Hill, R.T. (2008) Diversity and quorum-sensing signal production of Proteobacteria associated with marine sponges. Environ Microbiol 10, 75-86.

136. Mok, K.C., Wingreen, N.S., and Bassler, B.L. (2003) Vibrio harveyi quorum sensing: a coincidence detector for two autoinducers controls gene expression. EMBO J 22, 870-881.

137. Monds, R.D. and O'Toole, G.A. (2009) The developmental model of microbial biofilms: ten years of a paradigm up for review. Trends Microbiol 17, 73-87.

138. Montaser, R., Paul, V.J., and Luesch, H. (2013) Modular strategies for structure and function employed by marine cyanobacteria: characterization and synthesis of pitinoic acids. Org Lett $15,4050-4053$.

139. Montgomery, K., Charlesworth, J.C., LeBard, R., Visscher, P.T., and Burns, B.P. (2013) Quorum sensing in extreme environments. Life 3, 131-148.

140. Moran, M.A., Kujawinski, E.B., Stubbins, A., Fatland, R., Aluwihare, L.I., Buchan, A., Crump, B.C., Dorrestein, P.C., Dyhrman, S.T., Hess, N.J., Howe, B., Longnecker, K., Medeiros, P.M., Niggemann, J., Obernosterer, I., Repeta, D.J., and Waldbauer, J.R. (2016) Deciphering ocean carbon in a changing world. P Natl Acad Sci USA 113, 3143-3151.

141. Moré, M.I., Finger, L.D., Stryker, J.L., Fuqua, C., Eberhard, A., and Winans, S.C. (1996) Enzymatic synthesis of a quorum-sensing autoinducer through use of defined substrates. Science 272, 1655-1658.

142. Muras, A., López-Pérez, M., Mayer, C., Parga, A., Amaro-Blanco, J., and Otero, A. (2018a) High prevalence of quorum-sensing and quorum-quenching activity among cultivable bacteria and metagenomic sequences in the Mediterranean sea. Genes 9, 100. 
143. Muras, A., Mayer, C., Romero, M., Camino, T., Ferrer, M.D., Mira, A., and Otero, A. (2018b) Inhibition of Steptococcus mutans biofilm formation by extracts of Tenacibaculum sp. 20J, a bacterium with wide-spectrum quorum quenching activity. J Oral Microbiol 10.

144. Nakashima, T., Miyazaki, Y., Matsuyama, Y., Muraoka, W., Yamaguchi, K., and Oda, T. (2006) Producing mechanism of an algicidal compound against red tide phytoplankton in a marine bacterium gamma-proteobacterium. Appl Microbiol Biot 73, 684-960.

145. Natrah, F., Kenmegne, M.M., Wiyoto, W., Sorgeloos, P., Bossier, P., and Defoirdt, T. (2011a) Effects of micro-algae commonly used in aquaculture on acyl-homoserine lactone quorum sensing. Aquaculture 317, 53-57.

146. Natrah, F.M., Ruwandeepika, H.A., Pawar, S., Karunasagar, I., Sorgeloos, P., Bossier, P., and Defoirdt, T. (2011b) Regulation of virulence factors by quorum sensing in Vibrio harveyi. Vet Microbiol 154, 124-129.

147. Nealson, K.H., Platt, T., and Hastings, J.W. (1970) Cellular control of the synthesis and activity of the bacterial luminescent system. J Bacteriol 104, 313-322.

148. Neumann, A., Patzelt, D., Wagner - Döbler, I., and Schulz, S. (2013) Identification of new $N$ acylhomoserine lactone signalling compounds of Dinoroseobacter shibae DFL - 12T by overexpression of luxI Genes. Chembiochem 14, 2355-2361.

149. Newton, R.J., Griffin, L.E., Bowles, K.M., Meile, C., Gifford, S., Givens, C.E., Howard, E.C., King, E., Oakley, C.A., Reisch, C.R., Rinta-Kanto, J.M., Sharma, S., Sun, S., Varaljay, V., Vila-Costa, M., Westrich, J.R., and Moran, M.A. (2010) Genome characteristics of a generalist marine bacterial lineage. ISME J 4, 784-798.

150. Ng, W.L., Perez, L.J., Wei, Y., Kraml, C., Semmelhack, M.F., and Bassler, B.L. (2011) Signal production and detection specificity in Vibrio CqsA/CqsS quorum-sensing systems. Mol Microbiol 79, 1407-1417.

151. Nhan, D.T., Cam, D.T., Wille, M., Defoirdt, T., Bossier, P., and Sorgeloos, P. (2010) Quorum quenching bacteria protect Macrobrachium rosenbergii larvae from Vibrio harveyi infection. J Appl Microbiol 109, 1007-1016.

152. Oz, A., Sabehi, G., Koblizek, M., Massana, R., and Beja, O. (2005) Roseobacter-like bacteria in red and mediterranean sea aerobic anoxygenic photosynthetic populations. Appl Environ Microbiol 71, 344-353.

153. Paerl, H. (1982) Interactions with bacteria [Algae, cyanobacteria, ultrastructure, ecology, chemotaxis. Botanical Monographs.

154. Paggi, R.A., Martone, C.B., Fuqua, C., and De Castro, R.E. (2003) Detection of quorum sensing signals in the haloalkaliphilic archaeon Natronococcus occultus. FEMS Microbiol Lett 221, 4952.

155. Papenfort, K. and Bassler, B.L. (2016) Quorum sensing signal-response systems in Gramnegative bacteria. Nat Rev Microbiol 14, 576-588.

156. Papenfort, K., Silpe, J.E., Schramma, K.R., Cong, J.-P., Seyedsayamdost, M.R., and Bassler, B.L. (2017) A Vibrio cholerae autoinducer-receptor pair that controls biofilm formation. Nat Chem Biol 13.

157. Parsek, M.R., Val, D.L., Hanzelka, B.L., Cronan, J.E., Jr., and Greenberg, E.P. (1999) Acyl homoserine-lactone quorum-sensing signal generation. Proc Natl Acad Sci U S A 96, 43604365.

158. Patankar, A.V. and Gonzalez, J.E. (2009) Orphan LuxR regulators of quorum sensing. FEMS Microbiol Rev 33, 739-756.

159. Patzelt, D., Wang, H., Buchholz, I., Rohde, M., Gröbe, L., Pradella, S., Neumann, A., Schulz, S., Heyber, S., and Münch, K. (2013) You are what you talk: quorum sensing induces individual morphologies and cell division modes in Dinoroseobacter shibae. ISME J 7, 2274-2286. 
160. Paul, C. and Pohnert, G. (2011) Interactions of the algicidal bacterium Kordia algicida with diatoms: regulated protease excretion for specific algal lysis. PLoS One 6, e21032.

161. Pearson, J.P., Feldman, M., Iglewski, B.H., and Prince, A. (2000) Pseudomonas aeruginosa cellto-cell signaling is required for virulence in a model of acute pulmonary infection. Infect Immun 68, 4331-4334.

162. Perez-Rodriguez, I., Bolognini, M., Ricci, J., Bini, E., and Vetriani, C. (2015) From deep-sea volcanoes to human pathogens: a conserved quorum-sensing signal in Epsilonproteobacteria. ISME J 9, 1222-1234.

163. Peters, L., Konig, G.M., Wright, A.D., Pukall, R., Stackebrandt, E., Eberl, L., and Riedel, K. (2003) Secondary metabolites of Flustra foliacea and their influence on bacteria. Appl Environ Microbiol 69, 3469-3475.

164. Pietschke, C., Treitz, C., Foret, S., Schultze, A., Kunzel, S., Tholey, A., Bosch, T.C.G., and Fraune, S. (2017) Host modification of a bacterial quorum-sensing signal induces a phenotypic switch in bacterial symbionts. Proc Natl Acad Sci U S A 114, E8488-E8497.

165. Ploug, H., Grossart, H.-P., Azam, F., and Jørgensen, B.B. (1999) Photosynthesis, respiration, and carbon turnover in sinking marine snow from surface waters of Southern California Bight: implications for the carbon cycle in the ocean. Mar Ecol Prog Ser, 1-11.

166. Porsby, C.H., Nielsen, K.F., and Gram, L. (2008) Phaeobacter and Ruegeria species of the Roseobacter clade colonize separate niches in a Danish Turbot (Scophthalmus maximus)rearing farm and antagonize Vibrio anguillarum under different growth conditions. Appl Environ Microbiol 74, 7356-7364.

167. Purohit, A.A., Johansen, J.A., Hansen, H., Leiros, H.K., Kashulin, A., Karlsen, C., Smalas, A., Haugen, P., and Willassen, N.P. (2013) Presence of acyl-homoserine lactones in 57 members of the Vibrionaceae family. J Appl Microbiol 115, 835-847.

168. Puskas, A., Greenberg, E.P., Kaplan, S., and Schaefer, A.L. (1997) A quorum-sensing system in the free-living photosynthetic bacterium Rhodobacter sphaeroides. J Bacteriol 179, 75307537.

169. Ransome, E., Munn, C.B., Halliday, N., Cámara, M., and Tait, K. (2014) Diverse profiles of $N$ acyl-homoserine lactone molecules found in cnidarians. FEMS Mcrobiol Ecol 87, 315-329.

170. Rao, D., Webb, J.S., Holmstrom, C., Case, R., Low, A., Steinberg, P., and Kjelleberg, S. (2007) Low densities of epiphytic bacteria from the marine alga Ulva australis inhibit settlement of fouling organisms. Appl Environ Microbiol 73, 7844-7852.

171. Rasch, M., Buch, C., Austin, B., Slierendrecht, W.J., Ekmann, K.S., Larsen, J.L., Johansen, C., Riedel, K., Eberl, L., Givskov, M., and Gram, L. (2004) An inhibitor of bacterial quorum sensing reduces mortalities caused by Vibriosis in rainbow trout (Oncorhynchus mykiss, Walbaum). Syst Appl Microbiol 27, 350-359.

172. Rasmussen, B.B., Nielsen, K.F., Machado, H., Melchiorsen, J., Gram, L., and Sonnenschein, E.C. (2014) Global and phylogenetic distribution of quorum sensing signals, acyl homoserine lactones, in the family of Vibrionaceae. Mar Drugs 12, 5527-5546.

173. Rasmussen, T.B., Manefield, M., Andersen, J.B., Eberl, L., Anthoni, U., Christophersen, C., Steinberg, P., Kjelleberg, S., and Givskov, M. (2000) How Delisea pulchra furanones affect quorum sensing and swarming motility in Serratia liquefaciens MG1. Microbiology 146, 3237-3244.

174. Reidl, J. and Klose, K.E. (2002) Vibrio cholerae and cholera: out of the water and into the host. FEMS Microbiol Rev 26, 125-139.

175. Reveillaud, J., Maignien, L., Eren, A.M., Huber, J.A., Apprill, A., Sogin, M.L., and Vanreusel, A. (2014) Host-specificity among abundant and rare taxa in the sponge microbiome. ISME J 8, 1198-1209. 
176. Rezzonico, F. and Duffy, B. (2008) Lack of genomic evidence of AI-2 receptors suggests a non-quorum sensing role for luxS in most bacteria. BMC Microbiol 8, 154.

177. Rivas, M., Seeger, M., Jedlicki, E., and Holmes, D.S. (2007) Second acyl homoserine lactone production system in the extreme acidophile Acidithiobacillus ferrooxidans. Appl Environ Microbiol 73, 3225-3231.

178. Rivas, M.O., Vargas, P., and Riquelme, C.E. (2010) Interactions of Botryococcus braunii cultures with bacterial biofilms. Microb Ecol 60, 628-635.

179. Rolland, J.L., Stien, D., Sanchez-Ferandin, S., and Lami, R. (2016) Quorum sensing and quorum quenching in the phycosphere of phytoplankton: a case of chemical interactions in ecology. J Chem Ecol 42,1-11.

180. Romero, M., Avendano-Herrera, R., Magarinos, B., Camara, M., and Otero, A. (2010) Acylhomoserine lactone production and degradation by the fish pathogen Tenacibaculum maritimum, a member of the Cytophaga-Flavobacterium-Bacteroides (CFB) group. FEMS Microbiol Lett 304, 131-139.

181. Romero, M., Martin-Cuadrado, A.-B., and Otero, A. (2012) Determination of whether quorum quenching is a common activity in marine bacteria by analysis of cultivable bacteria and metagenomic sequences. Appl Environ Microbiol 78, 6345-6348.

182. Romero, M., Martin-Cuadrado, A.B., Roca-Rivada, A., Cabello, A.M., and Otero, A. (2011a) Quorum quenching in cultivable bacteria from dense marine coastal microbial communities. Fems Microbiol Ecol 75, 205-217.

183. Romero, M., Mayer, C., Muras, A., and Otero, A. (2015) Silencing bacterial communication through enzymatic quorum-sensing inhibition. In Quorum Sensing vs Quorum Quenching: A Battle with No End in Sight, pp. 219-236, Springer.

184. Romero, M., Muras, A., Mayer, C., Buján, N., Magariños, B., and Otero, A. (2014) In vitro quenching of fish pathogen Edwardsiella tarda AHL production using marine bacterium Tenacibaculum sp. strain 20J cell extracts. Dis Aquat Organ 108, 217-225.

185. Romero, M., Muro-Pastor, A.M., and Otero, A. (2011b) Quorum sensing $N$-acylhomoserine lactone signals affect nitrogen fixation in the cyanobacterium Anabaena sp. PCC7120. FEMS Microbiol Lett 315, 101-108.

186. Rosenberg, E., Koren, O., Reshef, L., Efrony, R., and Zilber-Rosenberg, I. (2007) The role of microorganisms in coral health, disease and evolution. Nat Rev Microbiol 5, 355.

187. Rui, H., Liu, Q., Ma, Y., Wang, Q., and Zhang, Y. (2008) Roles of LuxR in regulating extracellular alkaline serine protease A, extracellular polysaccharide and mobility of Vibrio alginolyticus. FEMS Microbiol Lett 285, 155-162.

188. Rui, H., Liu, Q., Wang, Q., Ma, Y., Liu, H., Shi, C., and Zhang, Y. (2009) Role of alkaline serine protease, Asp, in Vibrio alginolyticus virulence and regulation of its expression by LuxO-LuxR regulatory system. J Microbiol Biotechnol 19, 431-438.

189. Rutherford, S.T., van Kessel, J.C., Shao, Y., and Bassler, B.L. (2011) AphA and LuxR/HapR reciprocally control quorum sensing in Vibrios. Genes Dev 25, 397-408.

190. Saurav, K., Bar-Shalom, R., Haber, M., Burgsdorf, I., Oliviero, G., Costantino, V., Morgenstern, D., and Steindler, L. (2016a) In search of alternative antibiotic drugs: Quorum-quenching activity in sponges and their bacterial isolates. Front Microbiol 7, 416.

191. Saurav, K., Burgsdorf, I., Teta, R., Esposito, G., Bar - Shalom, R., Costantino, V., and Steindler, L. (2016b) Isolation of marine Paracoccus sp. Ss63 from the sponge Sarcotragus sp. and characterization of its quorum - sensing chemical - signaling molecules by LC - MS/MS analysis. Isr J Chem 56, 330-340. 
192. Saurav, K., Costantino, V., Venturi, V., and Steindler, L. (2017) Quorum sensing inhibitors from the sea discovered using bacterial $N$-acyl-homoserine lactone-based biosensors. Mar Drugs 15, 53.

193. Schaefer, A.L., Greenberg, E.P., Oliver, C.M., Oda, Y., Huang, J.J., Bittan-Banin, G., Peres, C.M., Schmidt, S., Juhaszova, K., Sufrin, J.R., and Harwood, C.S. (2008) A new class of homoserine lactone quorum-sensing signals. Nature 454, 595-599.

194. Schaefer, A.L., Hanzelka, B.L., Parsek, M.R., and Greenberg, E.P. (2000) Detection, purification, and structural elucidation of the acylhomoserine lactone inducer of Vibrio fischeri luminescence and other related molecules. Methods Enzymol 305, 288-301.

195. Schaefer, A.L., Taylor, T.A., Beatty, J.T., and Greenberg, E.P. (2002) Long-chain acylhomoserine lactone quorum-sensing regulation of Rhodobacter capsulatus gene transfer agent production. J Bacteriol 184, 6515-6521.

196. Schaefer, A.L., Val, D.L., Hanzelka, B.L., Cronan, J.E., Jr., and Greenberg, E.P. (1996) Generation of cell-to-cell signals in quorum sensing: acyl homoserine lactone synthase activity of a purified Vibrio fischeri LuxI protein. Proc Natl Acad Sci U S A 93, 9505-9509.

197. Schauder, S., Shokat, K., Surette, M.G., and Bassler, B.L. (2001) The LuxS family of bacterial autoinducers: biosynthesis of a novel quorum - sensing signal molecule. Mol Microbiol 41, 463-476.

198. Shao, C.P. and Hor, L.I. (2001) Regulation of metalloprotease gene expression in Vibrio vulnificus by a Vibrio harveyi LuxR homologue. J Bacteriol 183, 1369-1375.

199. Sharif, D.I., Gallon, J., Smith, C.J., and Dudley, E. (2008) Quorum sensing in Cyanobacteria: $N$ octanoyl-homoserine lactone release and response, by the epilithic colonial cyanobacterium Gloeothece PCC6909. ISME J 2, 1171-1182.

200. Shen, Y., Buick, R., and Canfield, D.E. (2001) Isotopic evidence for microbial sulphate reduction in the early Archaean era. Nature 410, 77-81.

201. Sheridan, C., Steinberg, D., and Kling, G. (2002) The microbial and metazoan community associated with colonies of Trichodesmium spp.: a quantitative survey. J Plankton Res 24, 913-922.

202. Simon, M., Grossart, H.-P., Schweitzer, B., and Ploug, H. (2002) Microbial ecology of organic aggregates in aquatic ecosystems. Aquat Microb Ecol 28, 175-211.

203. Skerratt, J., Bowman, J., Hallegraeff, G., James, S., and Nichols, P. (2002) Algicidal bacteria associated with blooms of a toxic dinoflagellate in a temperate Australian estuary. Mar Ecol Prog Ser 244, 1-15.

204. Slightom, R.N. and Buchan, A. (2009) Surface colonization by marine Roseobacters: integrating genotype and phenotype. Appl Environ Microbiol 75, 6027-6037.

205. Smith, D.C., Simon, M., Alldredge, A.L., and Azam, F. (1992) Intense hydrolytic enzyme activity on marine aggregates and implications for rapid particle dissolution. Nature 359, 139-142.

206. Sommerset, I., Krossoy, B., Biering, E., and Frost, P. (2005) Vaccines for fish in aquaculture. Expert Rev Vaccines 4, 89-101.

207. Srivastava, D., Harris, R.C., and Waters, C.M. (2011) Integration of cyclic di-GMP and quorum sensing in the control of vpsT and aphA in Vibrio cholerae. J Bacteriol 193, 6331-6341.

208. Srivastava, D. and Waters, C.M. (2012) A tangled web: Regulatory connections between quorum sensing and cyclic di-GMP.J Bacteriol 194, 4485-4493.

209. Steindler, L. and Venturi, V. (2006) Detection of quorum-sensing $N$-acyl homoserine lactone signal molecules by bacterial biosensors. FEMS Microbiol Lett 266, 1-9.

210. Surette, M.G., Miller, M.B., and Bassler, B.L. (1999) Quorum sensing in Escherichia coli, Salmonella typhimurium, and Vibrio harveyi: a new family of genes responsible for autoinducer production. Proc Natl Acad Sci U S A 96, 1639-1644. 
211. Svenningsen, S.L., Tu, K.C., and Bassler, B.L. (2009) Gene dosage compensation calibrates four regulatory RNAs to control Vibrio cholerae quorum sensing. EMBO J 28, 429-439.

212. Swartzman, A., Kapoor, S., Graham, A.F., and Meighen, E.A. (1990) A new Vibrio fischeri lux gene precedes a bidirectional termination site for the lux operon. J Bacteriol 172, 6797-6802.

213. Tait, K. and Havenhand, J. (2013) Investigating a possible role for the bacterial signal molecules $\mathrm{N}$-acylhomoserine lactones in Balanus improvisus cyprid settlement. Mol Ecol 22, 2588-2602.

214. Tait, K., Hutchison, Z., Thompson, F.L., and Munn, C.B. (2010) Quorum sensing signal production and inhibition by coral-associated Vibrios. Environ Microbiol Rep 2, 145-150.

215. Tait, K., Joint, I., Daykin, M., Milton, D.L., Williams, P., and Camara, M. (2005) Disruption of quorum sensing in seawater abolishes attraction of zoospores of the green alga Ulva to bacterial biofilms. Environ Microbiol 7, 229-240.

216. Tang, K., Su, Y., Brackman, G., Cui, F., Zhang, Y., Shi, X., Coenye, T., and Zhang, X.H. (2015) MomL, a novel marine-derived $N$-acyl homoserine lactonase from Muricauda olearia. Appl Environ Microbiol 81, 774-782.

217. Taylor, M.W., Schupp, P.J., Baillie, H.J., Charlton, T.S., de Nys, R., Kjelleberg, S., and Steinberg, P.D. (2004) Evidence for acyl homoserine lactone signal production in bacteria associated with marine sponges. Appl Environ Microbiol 70, 4387-4389.

218. Teasdale, M.E., Donovan, K.A., Forschner-Dancause, S.R., and Rowley, D.C. (2011) Grampositive marine bacteria as a potential resource for the discovery of quorum sensing inhibitors. Mar Biotechnol 13, 722-732.

219. Teasdale, M.E., Liu, J.Y., Wallace, J., Akhlaghi, F., and Rowley, D.C. (2009) Secondary metabolites produced by the marine bacterium Halobacillus salinus that inhibit quorum sensing-controlled phenotypes in gram-negative bacteria. Appl Environ Microbiol 75, 567572.

220. Tello, E., Castellanos, L., Arevalo-Ferro, C., and Duque, C. (2009) Cembranoid diterpenes from the Caribbean sea whip Eunicea knighti.J Nat Prod 72, 1595-1602.

221. Tello, E., Castellanos, L., Arevalo-Ferro, C., and Duque, C. (2012) Disruption in quorumsensing systems and bacterial biofilm inhibition by cembranoid diterpenes isolated from the octocoral Eunicea knighti. J Nat Prod 75, 1637-1642.

222. Teplitski, M., Krediet, C.J., Meyer, J.L., and Ritchie, K.B. (2016) Microbial interactions on coral surfaces and within the coral holobiont. In The Cnidaria, Past, Present and Future, pp. 331346, Springer.

223. Thiel, V., Brinkhoff, T., Dickschat, J.S., Wickel, S., Grunenberg, J., Wagner-Dobler, I., Simon, M., and Schulz, S. (2010) Identification and biosynthesis of tropone derivatives and sulfur volatiles produced by bacteria of the marine Roseobacter clade. Org Biomol Chem 8, 234-246.

224. Thiel, V., Kunze, B., Verma, P., Wagner-Dobler, I., and Schulz, S. (2009) New structural variants of homoserine lactones in bacteria. Chembiochem 10, 1861-1868.

225. Thole, S., Kalhoefer, D., Voget, S., Berger, M., Engelhardt, T., Liesegang, H., Wollherr, A., Kjelleberg, S., Daniel, R., Simon, M., Thomas, T., and Brinkhoff, T. (2012) Phaeobacter gallaeciensis genomes from globally opposite locations reveal high similarity of adaptation to surface life. ISME J 6, 2229-2244.

226. Thomas, K.V. and Brooks, S. (2010) The environmental fate and effects of antifouling paint biocides. Biofouling 26, 73-88.

227. Tice, M.M. and Lowe, D.R. (2004) Photosynthetic microbial mats in the 3,416-Myr-old ocean. Nature 431, 549-552.

228. Tinh, N.T.N., Yen, V.H.N., Dierckens, K., Sorgeloos, P., and Bossier, P. (2008) An acyl homoserine lactone-degrading microbial community improves the survival of first-feeding turbot larvae (Scophthalmus maximus L.). Aquaculture 285, 56-62. 
229. Torres, M., Rubio-Portillo, E., Anton, J., Ramos-Espla, A.A., Quesada, E., and Llamas, I. (2016) Selection of the $N$-acylhomoserine lactone-degrading bacterium Alteromonas stellipolaris PQQ-42 and of its potential for biocontrol in aquaculture. Front Microbiol 7, 646.

230. Tu, K.C. and Bassler, B.L. (2007) Multiple small RNAs act additively to integrate sensory information and control quorum sensing in Vibrio harveyi. Genes Dev 21, 221-233.

231. Vacelet, J. and Donadey, C. (1977) Electron microscope study of the association between some sponges and bacteria. J Exp Mar Bio Ecol 30, 301-314.

232. van Kessel, J.C., Rutherford, S.T., Shao, Y., Utria, A.F., and Bassler, B.L. (2013) Individual and combined roles of the master regulators AphA and LuxR in control of the Vibrio harveyi quorum-sensing regulon. J Bacteriol 195, 436-443.

233. Van Mooy, B.A., Hmelo, L.R., Sofen, L.E., Campagna, S.R., May, A.L., Dyhrman, S.T., Heithoff, A., Webb, E.A., Momper, L., and Mincer, T.J. (2012) Quorum sensing control of phosphorus acquisition in Trichodesmium consortia. ISME J 6, 422-429.

234. Vinoj, G., Vaseeharan, B., Thomas, S., Spiers, A.J., and Shanthi, S. (2014) Quorum-quenching activity of the AHL-lactonase from Bacillus licheniformis DAHB1 inhibits Vibrio biofilm formation in vitro and reduces shrimp intestinal colonisation and mortality. Mar Biotechnol 16, 707-715.

235. Wagner-Dobler, I., Thiel, V., Eberl, L., Allgaier, M., Bodor, A., Meyer, S., Ebner, S., Hennig, A., Pukall, R., and Schulz, S. (2005) Discovery of complex mixtures of novel long-chain quorum sensing signals in free-living and host-associated marine Alphaproteobacteria. Chembiochem 6, 2195-2206.

236. Wang, L., Ling, Y., Jiang, H.W., Qiu, Y.F., Qiu, J.F., Chen, H.P., Yang, R.F., and Zhou, D.S. (2013) AphA is required for biofilm formation, motility, and virulence in pandemic Vibrio parahaemolyticus. Int J Food Microbiol 160, 245-251.

237. Waters, C.M., Lu, W., Rabinowitz, J.D., and Bassler, B.L. (2008) Quorum sensing controls biofilm formation in Vibrio cholerae through modulation of cyclic di-GMP levels and repression of vpsT. J Bacteriol 190, 2527-2536.

238. Webster, N.S. and Thomas, T. (2016) The sponge hologenome. MBio 7, e00135-00116.

239. Wei, Y., Perez, L.J., Ng, W.-L., Semmelhack, M.F., and Bassler, B.L. (2011) Mechanism of Vibrio cholerae autoinducer-1 biosynthesis. ACS Chem Biol 6, 356-365.

240. Whiteley, M., Diggle, S.P., and Greenberg, E.P. (2017) Progress in and promise of bacterial quorum sensing research. Nature 551, 313-320.

241. Wieczorek, S.K. and Todd, C.D. (1998) Inhibition and facilitation of settlement of epifaunal marine invertebrate larvae by microbial biofilm cues. Biofouling 12, 81-118.

242. Wood, D.W. and Pierson, L.S. (1996) The phzI gene of Pseudomonas aureofaciens 30-84 is responsible for the production of a diffusible signal required for phenazine antibiotic production. Gene 168, 49-53.

243. Xavier, K.B. and Bassler, B.L. (2005) Interference with AI-2-mediated bacterial cell-cell communication. Nature 437, 750-753.

244. Yang, C.Y., Song, G.J., Zhu, Q., Liu, S.J., and Xia, C.H. (2016) The influence of bacterial quorumsensing inhibitors against the formation of the diatom-biofilm. Chemistry and Ecology 32, 169-181.

245. Yang, M., Frey, E.M., Liu, Z., Bishar, R., and Zhu, J. (2010) The virulence transcriptional activator AphA enhances biofilm formation by Vibrio cholerae by activating expression of the biofilm regulator VpsT. Infect Immun 78, 697-703.

246. Yang, Q. and Defoirdt, T. (2015) Quorum sensing positively regulates flagellar motility in pathogenic Vibrio harveyi. Environ Microbiol 17, 960-968.

247. Yang, Q., Han, Y., and Zhang, X.H. (2011) Detection of quorum sensing signal molecules in the family Vibrionaceae. J Appl Microbiol 110, 1438-1448. 
248. Yates, E.A., Philipp, B., Buckley, C., Atkinson, S., Chhabra, S.R., Sockett, R.E., Goldner, M., Dessaux, Y., Camara, M., Smith, H., and Williams, P. (2002) $N$-acylhomoserine lactones undergo lactonolysis in a pH-, temperature-, and acyl chain length-dependent manner during growth of Yersinia pseudotuberculosis and Pseudomonas aeruginosa. Infect Immun 70, 56355646.

249. Yildiz, F.H. and Visick, K.L. (2009) Vibrio biofilms: so much the same yet so different. Trends Microbiol 17, 109-118.

250. Zan, J., Choi, O., Meharena, H., Uhlson, C.L., Churchill, M.E., Hill, R.T., and Fuqua, C. (2015) A solo luxI-type gene directs acylhomoserine lactone synthesis and contributes to motility control in the marine sponge symbiont Ruegeria sp. KLH11. Microbiology 161, 50-56.

251. Zan, J., Cicirelli, E.M., Mohamed, N.M., Sibhatu, H., Kroll, S., Choi, O., Uhlson, C.L., Wysoczynski, C.L., Murphy, R.C., Churchill, M.E., Hill, R.T., and Fuqua, C. (2012) A complex LuxR-LuxI type quorum sensing network in a roseobacterial marine sponge symbiont activates flagellar motility and inhibits biofilm formation. Mol Microbiol 85, 916-933.

252. Zan, J., Fricke, W.F., Fuqua, C., Ravel, J., and Hill, R.T. (2011) Genome sequence of Ruegeria sp. strain KLH11, an $\mathrm{N}$-acylhomoserine lactone-producing bacterium isolated from the marine sponge Mycale laxissima. J Bacteriol 193, 5011-5012.

253. Zan, J.D., Heindl, J.E., Liu, Y., Fuqua, C., and Hill, R.T. (2013) The CckA-ChpT-CtrA phosphorelay system is regulated by quorum sensing and controls flagellar motility in the marine sponge symbiont Ruegeria sp KLH11. Plos One 8, 1932-6203.

254. Zehr, J.P., Mellon, M., Braun, S., Litaker, W., Steppe, T., and Paerl, H.W. (1995) Diversity of heterotrophic nitrogen fixation genes in a marine cyanobacterial mat. Appl Environ Microbiol 61, 2527-2532.

255. Zhai, C., Zhang, P., Shen, F., Zhou, C., and Liu, C. (2012) Does Microcystis aeruginosa have quorum sensing? FEMS Microbiol Lett 336, 38-44.

256. Zhu, J. and Mekalanos, J.J. (2003) Quorum sensing-dependent biofilms enhance colonization in Vibrio cholerae. Dev Cell 5, 647-656.

257. Zimmer, B.L., May, A.L., Bhedi, C.D., Dearth, S.P., Prevatte, C.W., Pratte, Z., Campagna, S.R., and Richardson, L.L. (2014) Quorum sensing signal production and microbial interactions in a polymicrobial disease of corals and the coral surface mucopolysaccharide layer. PLoS One 9, e108541. 